\title{
MÉXICO Y LA EXTRADICIÓN DE NACIONALES
}

\section{Rodrigo LABARDINI*}

RESUMEN: Los argumentos en contra de la extradición defienden la visión de que los nacionales estarán en desventaja en tribunales extranjeros o que otros sistemas jurídicos no aseguran que exista un juicio justo. Los países del common law están más dispuestos a extraditar a sus nacionales, mientras que los países del civil law sólo admitirán la extradición de sus nacionales en circunstancias excepcionales. Desde 1995 la política mexicana ha sido profundamente revisada, y el principio de aut dedere aut judicare en el tratado en vigor ha favorecido el castigo de presuntos criminales aunque no sean extraditados. La Suprema Corte de Justicia de México ha fallado para resolver una contradicción entre tribunales de menor jerarquía respecto de la facultad del Ejecutivo de extraditar a nacionales mexicanos. La solución, que el autor explica, es que el Código Penal mexicano no impide al Ejecutivo extraditar nacionales, sino que se aplica el artículo 9.1 del tratado en vigor.

ABSTRACT: Arguments against extradition favour the view that nationals will be in disadvantage before foreign tribunals, or that foreign legal systems do not afford the prisoner a fair trial. Common law countries are ready to extradite their nationals, whereas civil law systems will admit extradition of their nationals in exceptional circumstances. Since 1995 Mexican policy has been thoroughly revised, and the principle of aut dedere aut judicare in the extradition treaty in force has favoured the punishment of alleged criminals, even when not extradited. The Mexican Supreme Court has ruled $\mathrm{n}$ a contradiction of dicta by lower courts on the ability of the executive to extradite Mexican nationals. The solution, explained by the author, is that the Mexican Criminal Code does not prevent the Executive branch to extradite nationals, but rather article 9.1 of the Extradition Treaty in force is applicable.

RESUMÉ: Les arguments à l'encontre de l'extradition défendent la vision selon laquelle les nationaux seront désavantagés devant les tribunaux étrangers ou bien que les autres systèmes juridiques n'assurent pas l'existence d'un jugement juste. Les pays de commun law sont plus disposés à extrader leurs nationaux, alors que les pays de civil law admettront uniquement l'extradition de leurs nationaux dans des circonstances exceptionnelles. Depuis 1995, la politique mexicaine a été profondément revue et le principe de aut dedere aut judicare dans le traité en vigueur a encouragé le châtiment de criminels présumés, même s'ils n'étaient pas extradés. La Cour Suprême du Mexique a statué pour résoudre une contradiction entre les tribunaux des juridictions inférieures quant à la faculté de l'exécutif d'extrader des nationaux mexicains. La réponse, telle que l'auteur la décrit, est que le Code Pénal mexicain n'empêche pas l'exécutif d'extrader des nationaux, mais que c'est l'article 9.1 du traité en vigueur qui s'applique.

* Miembro del Servicio Exterior Mexicano de la Secretaría de Relaciones Exteriores. 
¿Quién es un rebelde? Un hombre que dice que no

Albert Camus.

Necessity is the mother of taking chances Mark Twain.

Los filósofos sólo han interpretado al mundo. Lo importante, sin embargo, es cambiarlo Karl Marx.

SUMARIO: I. Introducción. II. La extradición de nacionales. III. La extradición en México. IV. Conclusiones. V. Apéndice

\section{INTRODUCCIÓN}

Los problemas que rodean a la negativa de extraditar a nacionales son tan viejos como la extradición misma. ${ }^{1}$ Los orígenes de la regla pueden observarse desde tiempos remotos. A través de los siglos, diversos países han mantenido, de manera generalmente consistente, la práctica de no extraditar a sus nacionales. Pese a diversos convincentes argumentos en contra de dicha práctica, así como diferentes propuestas para modificar las políticas de los Estados sobre el tema, existen pocos indicios de que será abandonada en el futuro próximo.

Las controversias que rodean a la nacionalidad del fugitivo solicitado en extradición, como motivo para negar la petición, comienzan desde que se intenta determinar a quién debe aplicarse la regla. ${ }^{2}$ Algunos autores consideran que la negativa de extradición en razón de la nacionalidad del fugitivo no es un principio de derecho internacional universalmente reconocido, ${ }^{3}$ en tanto que otros estiman que, al menos en Estados con tradi-

1 Plachta, Michael, “(Non-) Extradition of Nationals: A Neverending Story?”, 13 Emory International Law Review 77, 1999.

2 Rationae personae, es necesario definir si el factor a tomar en consideración es el estatuto formal civil del fugitivo o si lo que debe imperar es la presencia de un vínculo sustantivo entre el fugitivo y el Estado requerido, como puede ser su domicilio. Por ejemplo, al adherirse a la Convención Europea de Extradición (1957), los países nórdicos (Dinamarca, Finlandia, Islandia, Noruega y Suecia) no sólo extendieron la definición de nacionales para incluir aquellos que normalmente residen en su territorio, sino también para incorporar a los nacionales y residentes de otros países nórdicos. Gilbert, Geoff, Transnational Fugitive Offenders in International Law, La Haya, Holanda, Martinus Nijhoff Publishers, 1998, p. 177.

3 Poncet, Dominique y Gully-Hart, Paul, "Legal Framework in Europe”, en Bassiouni, Cherif (ed.), International Criminal Law, 2a. ed., Nueva York, Transnational Publishers, Inc.-Adsley, 1999, t. II, pp. 284 y 285, no incluyen esta regla entre los principios de la extradición (entre los cuales sólo 
ción de derecho civil, ${ }^{4}$ el concepto sí ha sido reconocido como una regla de derecho internacional. ${ }^{5}$

Una de las afirmaciones más categóricas en este sentido es la que en 1961 expresara la Suprema Corte de Justicia de Austria: “También puede observarse que en asuntos penales existe la regla generalmente reconocida por el derecho internacional (artículo 9o. de la Constitución federal) de que los nacionales de un Estado nunca deben ser extraditados a otro Estado en cuyo territorio han cometido un delito" ${ }^{6}$

La negativa para conceder la extradición de nacionales impacta al derecho internacional al grado de que la Comisión Europea de Derechos $\mathrm{Hu}-$ manos, pese al artículo 5(3) de la Convención Europea de Derechos Humanos $(\mathrm{CEDH}),{ }^{7}$ convalidó la detención previa a juicio durante 35 meses de un nacional francés por autoridades suizas, señalando que si el fugitivo hubiera sido liberado existía el serio riesgo de que se fugara hacia Francia, desde donde sería imposible su extradición y donde tampoco habría garantía alguna de que fuera procesado por delitos cometidos en Suiza. ${ }^{8}$

El fundamento de la política, al negar la extradición de nacionales, esencialmente parece residir en considerar a los tribunales del Estado del nacional como los jueces naturales para juzgar cualquier delito cometido

mencionan: doble criminalidad, regla de la especialidad, excepción del delito político, juicio por tribunales de excepción, y la regla non bis in idem).

4 En oposición a Estados con tradición de derecho común (common law).

5 Cfr. Poncet, Dominique y Gully-Hart, Paul, op. cit., nota 3, p. 296; y Gilbert, Geoff, op. cit., nota 2, p. 176.

6 Service of Summons in Criminal Proceedings Case, ÖJZ, 1961/95 (Austria), en 38 International Law Reporter 133, 134 (1961) [énfasis añadido; traducción del autor].

7 "Toda persona detenida preventivamente o internada... deberá ser conducida sin dilación a presencia de un juez o de otra autoridad habilitada por la ley para ejercer poderes judiciales, y tendrá derecho a ser juzgada en un plazo razonable o a ser puesta en libertad durante el procedimiento. La puesta en libertad puede ser condicionada a una garantía que asegura la comparecencia del interesado en juicio". Artículo 5o. (3), Convención para la Protección de los Derechos Humanos y las Libertades Fundamentales, Roma, 4 de noviembre de 1950, 213 UNTS, 221. El texto de la CEDH ha sido enmendado de conformidad con el Protocolo núm. 3 (ETS núm. 45), que entró en vigor el 21 de septiembre de 1970, el Protocolo núm. 5 (ETS núm. 55), que entró en vigor el 20 de diciembre de 1971, y el Protocolo núm. 8 (ETS núm. 118), que entró en vigor el 1o. de enero de 1990, e integra también el texto del Protocolo núm. 2 (ETS núm. 44), el cual, de conformidad con su artículo 5o. (3) era parte integral de la CEDH desde su entrada en vigor el 21 de septiembre de 1970. Todas las disposiciones enmendadas o añadidas por dichos protocolos fueron sustituidas por el Protocolo núm. 11 (ETS núm. 155), a partir de su entrada en vigor el 1o. de noviembre de 1998. A partir de esta fecha, se abrogó el Protocolo núm. 9 (ETS núm. 140), que había entrado en vigor el 1o. de octubre de 1994, y el Protocolo núm. 10 (ETS núm. 146) dejó de tener propósito alguno.

8 Bonnechaux v. Switzerland, 3 Eur. Hum. Rights Rep. 259, 264 (1979) (solicitud núm. $8224 / 78)$. 
por aquél, la obligación del Estado de proteger a sus nacionales, así como el temor de que el nacional a extraditar pudiera enfrentarse en tribunales extranjeros con un idioma desconocido y prejuicios en su contra. ${ }^{9}$

En muchas ocasiones, se ha solicitado que los países que se oponen a extraditar a sus nacionales revalúen los beneficios de dicha práctica y rexaminen su validez con el fin de reconsiderar su continuación. ${ }^{10}$ Sin embargo, aún cuando dichas propuestas generalmente no han sido rechazadas, simple y llanamente los gobiernos de los Estados normalmente las han ignorado por razones relacionadas con políticas internas, consideraciones políticas y su soberanía. En esencia, normalmente consideran que sus intereses nacionales claramente superan a aquellos de la comunidad internacional.

En el caso de México, previo a 1994 no se había extraditado a mexicano alguno. ${ }^{11}$ En 1995, el gobierno mexicano realizó una revisión general de su política extraditoria y, en especial, de la práctica seguida en el caso de la extradición de ciudadanos mexicanos. ${ }^{12}$ A partir de entonces autorizó su extradición, pero sólo en casos excepcionales, de conformidad con el artículo 14 de la Ley de Extradición Internacional (LEI). ${ }^{13}$ Hasta el 9 de julio de 2001, el gobierno mexicano ha entregado en extradición a Esta-

9 Para un breve tratamiento del tema véase Labardini, Rodrigo, La magia del intérprete. Extradición en la Suprema Corte de Justicia de Estados Unidos de América: el caso Álvarez Macháin, México, Porrúa, 2000, pp. 28-32.

10 Algunas de las propuestas se formularon desde 1880. Cfr. Institute of International Law: Oxford Session, Sept. 9, 1880, 5 Annuaire de l'Institut de Droit Internationale 127, Res. 6 (1880), reproducido en Harvard Research in International Law, Draft Convention on Extradition, 29 American Journal of International Law 15, 296 (Supp. 1935) [en adelante Harvard Research].

11 Gobierno de México, Mexicos Fight Against the Scourge of Drugs, A Record of Achievement-1999, febrero de 2000, p. 55 [en adelante Mexico's Fight Against Drugs-1999] y Procuraduría General de la República, Mexico's Fight Against the Scourge of Drugs, A Record of Achievement, diciembre de 1998, p. 55 [en adelante Mexico's Fight Against Drugs-1998]. Ambos documentos, respectivamente dados a conocer en febrero de 2000 y diciembre de 1998, fueron distribuidos principalmente entre las oficinas legislativas de la Cámara de Representantes y del Senado del Congreso de Estados Unidos de América, así como entre oficinas y agencias de procuración de justicia en EUA. Fueron elaborados con información proporcionada por la Procuraduría General de la República (PGR) y las secretarías de Gobernación, Relaciones Exteriores (SRE), de la Defensa Nacional, de Marina y de Hacienda y Crédito Público.

12 Mexico's Fight Against Drugs-1999, nota 11, pp. 48-51.

13 El artículo 14 de la Ley de Extradición Internacional, Diario Oficial de la Federación, 29 de diciembre de 1975 (entrada en vigor: 30 de diciembre de 1975) [en adelante LEI], señala que "Ningún mexicano podrá ser entregado a un Estado extranjero sino en casos excepcionales a juicio del Ejecutivo". 
dos Unidos de América (EUA) a 16 ciudadanos mexicanos, ${ }^{14}$ y entregará a dos más cuando terminen de compurgar sus penas en México. ${ }^{15}$

Varios de los fugitivos apelaron sus extradiciones ${ }^{16}$ con resultados contradictorios. En un caso ${ }^{17}$ se sostuvo que la extradición ${ }^{18}$ es una facultad discrecional del Ejecutivo. En otro ${ }^{19}$ se indicó que dicha facultad se encontraba limitada por el artículo 4o. del Código Penal Federal (CPF) ${ }^{20}$ que prescribe que los delitos cometidos por mexicanos en el exterior "serán penados en la república".

Ante esta contradicción de criterios, la Suprema Corte de Justicia de la Nación (SCJN) resolvió el 18 de enero de $2001^{21}$ que el artículo 4o., CPF, no impide la extradición a EUA de mexicanos acusados de haber cometido algún delito en ese país. ${ }^{22}$ La SCJN indicó que el artículo 4o., $\mathrm{CPF}$, no constituye una limitante a las facultades del Ejecutivo para autorizar la extradición de ciudadanos mexicanos, ya que establece una medida (esencialmente procedimental) definiendo que cuando un mexicano sea juzgado en México por un delito que hubiera cometido en el exterior,

14 Cinco de ellos durante la administración del presidente Fox, PGR, Boletín de Prensa 436/01, 25 de junio de 2001: Fernando Farías, Ángel Salvador Molina Páramo, Everardo Arturo Páez Martínez, Rafael Camarena García y Miguel Ángel Martínez Martínez, solicitados por los delitos de asociación delictuosa y contra la salud. Cfr. además los boletines de prensa de PGR 152/01 (13 de marzo de 2001) y 397/01 (12 de junio de 2001).

15 Jesús Emilio Rivera y Roberto Beltrán, ambos por delitos contra la salud. Mexico's Fight Against Drugs-1999..., cit., nota 11, p. 50. Adicionalmente, véase Secretaría de Relaciones Exteriores (México) y White House Office for the National Drug Control Policy (ONDCP), US/Mexico Bi-National Cooperation Against Illicit Drugs. Main Results and Performance Measurements of Effectiveness, noviembre de 2000, p. 8 [en adelante US-Mexico 1995-2000 Main Results]. Las versiones en español e inglés del documento pueden consultarse, respectivamente, en http://usembassy-mexico.gov/sdlegado.html; $y$ http://www.whitehousedrugpolicy.gov/publications/international/binational1995to2000/binational1995to2000.pdf.

16 Hubo mexicanos que consintieron en ser extraditados. Secretaría de Relaciones Exteriores, Boletín de Prensa B-130, 26 de abril de 1996.

17 Segundo Tribunal Colegiado en Materia Penal para el Segundo Distrito (Toluca, Estado de México).

18 Incluyendo la de nacionales mexicanos.

19 Primer Tribunal Colegiado en Materia Penal para el Primer Distrito (México, D. F.).

20 El texto completo del precepto se transcribe más adelante, en el apartado "Ref520707701 Lh".

21 Véase entre otros, Lizárraga, Daniel, "Aprueba Corte extradición de mexicanos", Reforma, ciudad de México, 19 de enero de 2001.

22 Tesis Jurisprudencial 11/2001, 18 de enero de 2001, y Contradicción de tesis 44/2000-PL. Entre las sustentadas por el Segundo Tribunal Colegiado en Materia Penal del Segundo Circuito y el Primer Tribunal Colegiado en Materia Penal del Primer Circuito, 18 de enero de 2001. Mayoría de diez votos; votó en contra Humberto Román Palacios. Ponente: Olga Sánchez Cordero de García Villegas. Secretario: José Luis Vázquez Camacho. 
será juzgado y sancionado de conformidad con la legislación nacional y no la extranjera. ${ }^{23}$

\section{El sentido práctico de la sentencia consiste en que, si en algún mo-} mento pudo serlo, la nacionalidad mexicana no es más un obstáculo para que proceda la extradición hacia otro país. ${ }^{24}$ Asimismo refrendó las facultades del Ejecutivo y, además, debido a que se anunció el 18 de enero, logró evitar su vinculación directa con el proceso estadounidense de "certificación" de la cooperación antinarcóticos de otros países. ${ }^{25}$

La resolución, que hubo de ser elaborada más de una vez, ${ }^{26}$ fue favorablemente recibida en diversos medios mexicanos ${ }^{27} \mathrm{y}$ estadounidenses $\mathrm{y}$

23 Contradicción de tesis 44/2000-PL, nota anterior.

24 En otro tema de importancia en la relación extraditoria bilateral (véase el Apéndice) es de señalar que la expresada resolución no alude a criterios sustentados por algunos tribunales mexicanos impidiendo la extradición en caso de que se aplique la cadena perpetua al extraditado por considerarla una pena inusitada y, por tanto, entre las prohibidas por el artículo 22 de la Constitución Política de los Estados Unidos Mexicanos (CPEUM). Labardini, Rodrigo, “Mexico's Supreme Court Allows the Extradition of Mexican Nationals", 17 International Enforcement Law Reporter 106 (march 2001), pp. 113 y 114 [en adelante Court Allows Extradition of Nationals]. Se cree que entre agosto y septiembre de 2001, la SCJN resolverá el asunto en forma definitiva. Existen informes de que la resolución podría ser en el sentido de permitir estos casos. Aranda, Jesús, "Aprobará la SCJN extraditar a EUA a mexicanos que podrían ser condenados a cadena perpetua”, La Jornada, 16 de julio de 2001, p. 9.

25 EUA tiene como límite el 1o. de marzo de cada año para dar a conocer el resultado de su evaluación anual de la cooperación antinarcóticos de otros países, mejor conocida como certificación. Conocida como la sorpresa de febrero, "Drugs Shock", The Economist, 4 de marzo de 2000, pp. 38 y 39, en diversos medios se estima que los países (México incluido) anuncian alguna nueva y decidida iniciativa antidrogas en febrero con el fin de que EUA considere favorablemente su actuación al realizar la "certificación". Seper, Jerry, "Mexico extradites drug suspect as yearly certification approaches", The Washington Times, 10 de febrero de 2000, p. A4. EUA ha señalado que la certificación ha probado ser un instrumento efectivo de política internacional, aunque brusco y ríspido, para fomentar la cooperación antinarcóticos, y que, antes del 1o. de marzo, "ha observado que los países introducen legislación, aprueban leyes, erradican cosechas ilícitas y capturan a capos narcotraficantes antes difíciles de localizar. Esto no es coincidencia. Estos países saben que sus acciones tendrán un impacto en las decisiones presidenciales sobre la certificación. También saben qué es lo que EUA espera de ellos". Beers, Rand (secretario asistente para Narcóticos y Procuración de Justicia Internacionales, Depto. de Estado de EUA), "Statement Before the Committee on Foreign Relations", Review of the Anti-Drug Certification Process, Hearing Before the Committee On Foreign Relations, United States Senate, 107th Congress, 1st Session, 1o. de marzo de 2001, pp. 26 y 28. Para un detallado análisis de la "certificación", véase Labardini, Rodrigo, "El proceso estadounidense sobre certificación de otros Estados en la lucha contra el narcotráfico", El Foro, Órgano de la Barra Mexicana, Colegio de Abogados, A. C., 10a. época, t. XI, núm. 1, primer semestre de 1998, México, pp. 129-182.

26 Es significativo que la ministro ponente de la SCJN, encargada de elaborar la resolución, presentó en diciembre de 2000 un primer proyecto. Sin embargo, ante las observaciones de otros ministros decidió retirarlo y volver a presentar otro más. Lizárraga, Daniel, "Inicia Corte, debate sobre extraditables", Reforma, ciudad de México, 18 de enero de 2001.

27 Clemente Valdés, coordinador de la Comisión de Derecho Constitucional de la Barra Mexi- 
se le considera un refrendo de la voluntad del gobierno mexicano, y no sólo del Poder Ejecutivo, ${ }^{28}$ para combatir al narcotráfico y delitos asociados. ${ }^{29}$ En este sentido, es de mencionar que a la expresada resolución de la SCJN se atribuye el haber generado suficiente grado de temor y desconfianza entre delincuentes como para que éstos modificaran sus actividades. Así, se indica que Joaquín Guzmán, El Chapo, huyó del penal de máxima seguridad de Puente Grande, ya que "estaba desesperado, pues pronto se resolverían los últimos procesos en su contra que creía podría ganar, pero con la resolución de la Suprema Corte de Justicia de la Nación que permite la extradición de connacionales a Estados Unidos de América, El Chapo podría ser sometido a este proceso". ${ }^{30}$

En el presente estudio analizaremos un panorama general del tema, y la problemática que rodea a la extradición de nacionales, para luego revisar con mayor detalle la práctica mexicana, en especial la última década, y la referida resolución de la SCJN.

\section{LA EXTRADICIÓN DE NACIONALES ${ }^{31}$}

\section{Los nacionales del Estado requerido reciben un tratamiento especial} cuando se trata de su posible extradición. Esto se debe a que muchas ve-

cana, Colegio de Abogados, consideró que con esta resolución lo único que se hizo "fue convalidar jurídicamente la extradición a Estados Unidos de América, no veo por qué la sociedad mexicana tenga que proteger a ningún delincuente porque sea mexicano; me parece que protegerlo es una vergüenza que va contra el sentido elemental de la humanidad", Torres, Mario, "Aceptan extraditar a mexicanos a EU", El Universal, ciudad de México, 19 de enero de 2001.

28 Ante la aprobación de la resolución en comento, la ministro ponente de la SCJN, Olga Sánchez Cordero, afirmó que no existe ninguna posibilidad de ser amenazados por narcotraficantes y extraditables por este fallo, debido a que México todavía no llega a los niveles de narcotráfico en Colombia. Afirmó que "La verdad es que no habíamos pensado en esa posibilidad, pero ahora que me lo comenta, creo que será importante tenerlo en cuenta". Jiménez, Norma, "Descartan ministros de la SCJN represalias de narcos", Milenio Diario, ciudad de México, 22 de enero de 2001.

29 De hecho, durante muchos años, tanto la administración como el Congreso estadounidenses consideraban que México se había constituido en un refugio para criminales debido al poco número de extradiciones de México hacia EUA y a la reiterada negativa para extraditar a mexicanos. Véanse infra notas 122-126.

30 Funcionarios de la Secretaría de Seguridad Pública y de la Comisión Nacional de Derechos Humanos, citados en María Idalia Gómez y Alfredo Joyner, “A El Güero y a El Texas les faltó tiempo para huir", Milenio Diario, 23 de enero de 2001. Según se indicó, El Güero Palma y Arturo Martínez Herrera, El Texas, no enfrentaban este problema y tal parece que por eso no pensaron en huir al mismo tiempo que su compañero. Idem.

31 Para una exposición más detallada, consúltese Plachta, op. cit., nota 1. También Piombo, Horacio Daniel, Tratado de la extradición, Buenos Aires, Ediciones Depalma, 1998; y Piombo, Horacio Daniel, La extradición de nacionales, Buenos Aires, Ediciones Depalma, 1974. 
ces los Estados y su propia población tienen reservas y preocupación por los sistemas jurídicos extranjeros ${ }^{32}$ que llevan a considerar que los connacionales se encuentran en desventaja al tratar con tribunales extranjeros. ${ }^{33}$

A diferencia de la excepción de extradición por delito político o delitos militares o fiscales, la exención de nacionales de ser extraditados radica con el individuo y no con la naturaleza del delito. La excepción de nacionales puede ser de dos formas: absoluta y cualificada. Puede encontrarse a nivel constitucional en algunos Estados, ${ }^{34}$ en $\operatorname{tratados}^{35} \mathrm{o}$ en legislación interna. ${ }^{36}$

En defensa de la política de negar la extradición de los nacionales del Estado requerido, se argumenta la reserva y preocupación por sistemas jurídicos extranjeros que llevan a considerar que los connacionales se encuentran en desventaja al tratar con tribunales extranjeros. Razones para ello pueden ser una posible falta de objetividad del Estado requirente al juzgarle, desconocimiento del idioma, costumbres y proceso jurídico locales, o por cualesquiera otras consideraciones como pueden ser posibles prejuicios raciales o legales que pueden darse en jurisdicciones extranjeras. ${ }^{37}$

Adicionalmente, los Estados pueden considerar que los sistemas jurídicos extranjeros carecen de reglas y salvaguardas suficientes para garantizar no sólo un proceso justo sino que no cuente con cierta carga mínima

32 Gilbert, op. cit., nota 2, p.179.

33 Shearer, Iván, Extradition in International Law, 1971, pp. 95 y 96.

34 Por ejemplo, al volver a crearse la República de Eslovenia, cuando se desmembró la exURSS, se estableció en el artículo 47 de su Constitución Política que ningún ciudadano de Eslovenia podía ser extraditado, y que la extradición de extranjeros sólo sería permisible en los casos definidos por acuerdos internacionales. En el artículo 48, igualmente se garantiza el derecho de asilo de extranjeros y apátridas, perseguidos por sus posiciones sobre derechos humanos y libertades fundamentales.

35 Véase el Tratado de Extradición Modelo de Naciones Unidas, 14 de diciembre de 1990, 30 International Legal Materials 1407 (también puede consultarse en Swart, Bert, Refusal of Extradition and the United Nations Model Treaty on Extradition, 1992 Netherlands Yearbook of International Law 75). El artículo 4o. (a) del tratado modelo considera a la nacionalidad como un posible fundamento para rehusar la extradición. Agrega que, a solicitud de la parte requirente, la parte requerida deberá someter el caso ante sus autoridades competentes con el fin de adoptar las medidas apropiadas en contra del nacional. Asimismo, entre muchos ejemplos, el artículo 6o. del Tratado de Extradición entre el Reino de España y la República de Nicaragua (Managua, 12 de noviembre de 1997 (BOE 235/2000, de 30 de septiembre)), dispone que "Cuando la persona buscada sea de la nacionalidad de la parte requerida, ésta no estará obligada a extraditarla".

36 El Código Penal venezolano dispone que "La extradición de un venezolano no podrá concederse por ningún motivo, pero deberá ser enjuiciado en Venezuela a solicitud de parte agraviada o del Ministerio Público, si el delito que se le imputa mereciera pena por ley venezolana". Secretaría de Relaciones Exteriores (comp.), Límites de la jurisdicción nacional, México, 1993, vol. II, p. 100.

37 Cfr. Lizárraga, Daniel, "Respaldan ministros extraditar mexicanos", Reforma, ciudad de México, 18 de enero de 2001. 
de derechos para el acusado. ${ }^{38}$ En este sentido, la Suprema Corte de Justicia de EUA, al decidir casos de extradición, ocasionalmente ha tomado en cuenta y sopesado el hecho de que en un sistema extranjero el acusado carezca de las protecciones jurídicas de las que podría gozar en EUA. Al comparar la extradición interestatal con la internacional ha indicado que al entregar a un acusado a las autoridades de un Estado hermano, no se le envía a una jurisdicción ${ }^{39}$ extranjera (y añadiríamos desconocida) "con leyes que sus estándares pueden condenar y repudiar". 40

Por este motivo, los Estados requeridos prefieren ser quienes los procesen penalmente, procurando de esta forma satisfacer dos necesidades a veces contrapuestas: el deseo del Estado requirente de castigar a la persona y el derecho de ésta a un juicio imparcial y objetivo. Esto parece reflejar la preocupación de algunos Estados al colocar a sus nacionales en tribunales extranjeros donde pueden encontrarse en desventaja. ${ }^{41}$

Conforme a la práctica seguida en algunos Estados, principalmente de tradición jurídica del derecho civil, ${ }^{42}$ el Estado tiene la posibilidad de

38 Por contrapartida, cuando las autoridades de un Estado desconfían de un sistema extranjero de procuración de justicia, o se "frustran" por su inacción (Nadelman, op. cit., nota 110), en muchas ocasiones recurren a métodos irregulares (e ilegales) para lograr la aprehensión del fugitivo, incluyendo el uso de ardides y garlitos (como la "Operación Casablanca", véanse infra notas 161-163) y secuestros transfronterizos (véase Labardini, Rodrigo, "La impaciencia del fiscal: el secuestro transfronterizo", en Jurídica, Anuario del Departamento de Derecho de la Universidad Iberoamericana, núm. 28, 1998, México, pp. 381-430).

39 El término "jurisdicción" es frecuente tanto en derecho interno como en derecho internacional, aunque con diferentes matices. Al interior de un país, se refiere uno a jurisdicción federal, estatal o municipal, debido a la organización jurídico-política de un Estado. Asimismo, encontramos distribución de las competencias en una sola demarcación territorial, con tribunales mercantiles, civiles, administrativos o penales. En materia internacional, "jurisdicción" se refiere a la adjudicación de autoridad a un Estado como un todo y no a las distintas unidades políticas que la integran. En tanto México es una federación, Francia no lo es. En caso que un extranjero sea juzgado en Orizaba o Guadalajara, o en Marsella o en París, no da lugar a una discusión internacional sobre cuestiones de competencia y jurisdicción internas. El punto estriba más bien en determinar si la persona puede ser juzgada por otro Estado y no en definir qué tribunal de ese Estado debe enjuiciarle. A mayor abundamiento, véase Labardini, Rodrigo, "Reflexiones sobre jurisdicción en derecho internacional. tendencias y problemas actuales", El Foro, órgano de la Barra Mexicana, Colegio de Abogados, A. C., México, 11a. época, t. XIII, núm. 1, primer semestre, 2000, pp. 168.

40 "...in delivering up an accused person to the authorities of a sister State [the courts] are not sending him for trial to an alien jurisdiction, with laws which our standards might condemn, but are simply returning him to be tried, still under the protection of the Federal Constitution but in the manner provided by the State against the laws of which it is charged that he has offended", Biddinger $v$. Commissioner of Police, 245 U. S. 128, 133 (1917) [énfasis añadido].

41 Shearer, op. cit., nota 33, pp. 95 y 96.

42 Cfr. supra notas 3-9; aunque Bassiouni, Cherif, International Extradition: United States Law and Practice, 3a. ed., Nueva York, Oceana Publications, Inc., 1996, p. 588 [en adelante US Law], sólo alude a Estados europeos. 
otorgar cierta protección a sus nacionales y consecuentemente puede negar su extradición. ${ }^{43}$ Sin embargo, y como contrapartida, el Estado requerido normalmente deberá procesar a la persona buscada por el requirente, siempre que la conducta perseguida sea extraditable de conformidad con el propio tratado de extradición.

La práctica de rechazar la extradición por motivos de nacionalidad se inició en Francia. Posiblemente derivado de este hecho es que también se ha indicado que los Estados con tradición jurídica de derecho común (common law) regularmente extraditan a sus nacionales. ${ }^{44}$

Pese a ello, en ocasiones, países como EUA habían insistido en que en los tratados de extradición se incluyan cláusulas que eximan a los países de la obligación de extraditar a sus nacionales. ${ }^{45}$ Lo que también parece claro es que, sin importar que se prohíba o no la extradición, los tribunales revisarán con mayor detenimiento y en forma más estrecha si la persona a extraditar es connacional suyo. Así, puede intuirse que si el afectado es un nacional de un tercer Estado, ${ }^{46}$ probablemente no reciba la misma consideración que los nacionales del Estado requerido. ${ }^{47}$

Sin embargo, y como países de la tradición del common-law, EUA y Canadá en general no ponen reparos a la extradición de sus nacionales, ${ }^{48}$ pues sus autoridades tienen claras facultades para hacerlo. ${ }^{49}$ Esta situa-

43 Bassiouni, Cherif, International Extradition and World Public Order, 1974 (en adelante IE and WPO), p. 435; Shearer, op. cit., nota 33, p. 94.

44 Véase Bassiouni, Cherif y Wise, Edward, Aut Dedere, Aut Judicare, The Duty to Extradite or Prosecute in International Law, La Haya, Holanda, Martinus Nijhoff Publishers, 1995; así como Bassiouni, IE and WPO..., cit., nota 43, p. 435; y Buser, Wade, "The Jaffe Case and the Use of International Kidnapping as an Alternative to Extradition", 14 Georgia Journal of International and Comparative Law 357, 365, 1984.

45 Kester, John, "Some Myths of United States Extradition Law", 76 The Georgetown Law Journal 1441, 1479, 1988. Por ejemplo, esta limitación se incluye en el artículo 9o. del Tratado de Extradición México-EUA vigente (Diario Oficial de la Federación: 26 de febrero de 1980 y 16 de mayo de 1980. Su texto puede consultarse en Secretaría de Relaciones Exteriores y H. Senado de la República, Tratados Ratificados y Convenios Ejecutivos Celebrados por México [en adelante Tratados y Convenios de México], t. XXII (1977-1978), México, SRE, 1976, pp. 613-626; así como en el artículo II de la Convención de Extradición del 26 de octubre de 1901 entre EUA y Bélgica, 32 Stat. 1894, USTS 409.

46 Es decir, ni del Estado requirente ni del requerido.

47 Labardini, op. cit., nota 9, p. 29. En el caso de EUA, los tribunales prácticamente han recogido este parecer al tenor siguiente: "no vemos razón alguna para separarnos de lo que aquí marca el derecho, ya que de la Pava no es estadounidense ni panameño y ninguna de las partes en el tratado ha objetado la extradición de de la Pava". United States v. Toro, 840 F.2d 1221, 1215 (5th Cir. 1988) [t.a.].

48 Labardini, op. cit., nota 9, p. 29.

49 McDowell, E., Digest of United States Practice in International Law, 1976, p. 118. 
ción contrasta con la legislación de varios países latinoamericanos y europeos, donde existen disposiciones constitucionales y en legislación secundaria que expresamente prohíben la extradición de nacionales. ${ }^{50}$

Por esta razón, en años recientes, al negociar nuevos tratados de extradición, EUA ha buscado incluir cláusulas que permitan la extradición de nacionales, o que por lo menos permitan cierta discreción para hacerlo.$^{51}$ En este sentido, el Departamento de Justicia de EUA ha reiterado la necesidad de evitar que EUA se convierta en un santuario para estadounidenses que hubieran cometido delitos en el exterior y que no podrían ser extraditados conforme a los tratados de extradición más viejos. ${ }^{52}$

En los tratados de extradición normalmente se incluyen tres tipos de disposiciones sobre nacionales. La primera indica que la extradición puede ser otorgada tratándose de "cualquier persona", incluyendo por lo tanto a sus nacionales. ${ }^{53} \mathrm{El}$ segundo mecanismo establece que ninguna de las dos partes contratantes está obligada a extraditar a sus nacionales. ${ }^{54}$ Éste es el sistema más frecuente. Un tercer tipo, similar al segundo, añade que el Poder Ejecutivo de un Estado puede extraditar a sus nacionales si decidiera que resulta provechoso para las relaciones bilaterales con el Estado requirente. .5

En el caso estadounidense, ${ }^{56}$ esta posición puede reflejar el hecho de que el total de solicitudes de extradición que presenta EUA equivalen a menos de la mitad de las que recibe, ${ }^{57} \mathrm{o}$ bien puede representar una no

50 Por ejemplo, en Europa: Francia, Alemania, Austria y Bélgica; en América Latina: Brasil, Ecuador, Panamá y Venezuela. Adicionalmente, véase Borek, Jamison (consultor Jurídico Adjunto del Departamento de Estado de EUA), Testimony before the Subcomm. on Crim. Justice, Drug Policy and Human Resources, Comm. on Gov. Reform, US House of Representatives, 23 de junio de 1999.

51 Kester, op. cit., nota 45, p. 1475.

52 Reform of the Extradition Laws of the United States: Hearings on H. R. 2643, Subcomm.on Crime, House Committee on the Judiciary, 98th Cong., 1st Sess. 34, 1983, p. 35.

53 Por ejemplo, la Suprema Corte de Justicia de EUA ha señalado que las autoridades estadounidenses no pueden rehusar la extradición sólo porque la persona a extraditar sea nacional suyo. Charlton v. Kelly, 229 US 447, 457 (1913).

54 No obstante, si bien no están obligados a extraditar, el Estado requerido puede hacerlo si así lo estima conveniente.

55 Labardini, op. cit., nota 9, p. 32.

56 Sobre México, véase infra III, 1.

57 En el año fiscal de 1983, EUA presentó 239 solicitudes y el Depto. de Justicia recibió sólo 99 después de ser revisadas por el Depto. de Estado. Sin embargo, para 1985, el número de solicitudes recibidas había crecido a 489. Attorney General Annual Report, 1983, p. 70, Attorney General Annual Report, 1985, p. 82. Es de señalar que la relación extraditoria bilateral con México ha crecido en forma importante en los últimos años. Durante 1997, 1998 y 1999, EUA solicitó a México a 144 personas en extradición, y México presentó 106 solicitudes. Mexico's Fight Against Drugs, 1999, nota 11, pp. 48 y 49 . Véanse texto y notas $130-134$. 
desconocida práctica del Departamento de Estado de EUA de estar dispuesto "a sacrificar la seguridad de ciudadanos en lo particular frente a las relaciones internacionales". 58

Por lo anterior, EUA usualmente extradita a sus nacionales, ${ }^{59}$ aún cuando la contraparte no otorgue reciprocidad ${ }^{60}$ En este sentido, la Suprema Corte de Justicia de EUA ha señalado que la práctica italiana de no extraditar a ciudadanos italianos resulta inmaterial para considerar las obligaciones de EUA conforme al tratado de extradición respectivo. ${ }^{61}$ De hecho se ha indicado que las autoridades estadounidenses han manifestado casi un entusiasmo para extraditar a sus propios nacionales. ${ }^{62}$ Por estos motivos, no sorprende que entre el 10 y 20 por ciento de personas extraditadas desde EUA sean ciudadanos estadounidenses. ${ }^{63}$

No obstante, debemos destacar que la posición estadounidense ha sufrido cierta transformación. En 1913, la SCJ-EUA indicó que ningún principio de derecho internacional o disposición constitucional eximía a ciudadanos estadounidenses de procesos extraditorios salvo que hubiera disposición expresa en el tratado correspondiente. ${ }^{64}$ Años después, la SCJ-EUA redujo la posibilidad y señaló que la Constitución de EUA niega al Poder Ejecutivo facultades para entregar a ciudadanos estadounidenses, a menos que una ley o tratado le imponga la obligación de hacerlo, o bien goce explícitamente de discreción para efectuar la entrega. ${ }^{65}$

Pese a diversas explicaciones ofrecidas para justificar la no extradición de nacionales ${ }^{66}$ debe cuestionarse si continúa siendo válida dicha prohibición para extraditar a un fugitivo. Al establecer la política de fron-

58 Kester, op. cit., nota 45, p. 1475 [t. a.].

59 Siempre que los delitos estén incluidos en un tratado de extradición o en su legislación interna. In re Edmondson, 352 F. Supp. 22 (1972, DC Minn). Asimismo, véase Kruk, Theresa y Donaldson, Russell, Test Of "Dual Criminality" Where Extradition to or From Foreign Nation is Sought, 132 ALR Fed. 525.

60 Blakesley, A Conceptual Framework for Extradition and Jurisdiction over Extraterritorial Crimes, 1984, Utah L. Review 685, 734 (nota 133). No obstante, otro autor considera que en principio los EUA no otorgan la extradición de sus nacionales a menos que el Estado requirente otorgue reciprocidad. Buser, op. cit., nota 44, pp. 365 y 366.

61 Charlton v. Kelly, 229 US 447, 1913.

62 Kester, op. cit., nota 45, pp. 1474 y 1475 [t. a.].

63 Hearings on H.R. 5227, Subcomm. on Crime, House Committee on the Judiciary, 97th Cong., 2d Sess., 1982, p. 36.

64 Charlton v. Kelly, 229 US 447, 1913. Si el tratado explícitamente otorga discreción a las autoridades de EUA, las mismas pueden extraditar o no a sus nacionales. In re Russell, 805 F.2d 1215, 1218 (5th Cir. 1986).

65 Valentine v. United States ex rel. Niedecker, 299 US 5, 1938.

66 Cfr. Piombo, La extradición de nacionales, nota 31. 
teras abiertas en 1992, en la Comunidad Europea había Estados que rehusaban extraditar a nacionales en cualesquiera circunstancias, ${ }^{67}$ y los países nórdicos se negaban a extraditar no sólo a sus nacionales sino también a los nacionales de otros países nórdicos. ${ }^{68}$ Sin embargo, la Convención de la Unión Europea sobre Extradición entre Miembros Estados (1996) dispone en su artículo 7.1 que la extradición no puede ser negada debido a que la persona reclamada sea nacional del Estado miembro requerido. ${ }^{69}$

Adicionalmente, otros Estados han modificado su legislación con el fin de permitir la extradición de nacionales. El artículo VIII del Tratado de Extradición Colombia-EUA suscrito el 14 de septiembre de 1979 contemplaba la extradición de nacionales. Inicialmente se le consideró como un medio para terminar con problemas de corrupción y narcotráfico en Colombia. ${ }^{70}$ Sin embargo, varios legisladores se opusieron por considerarlo una violación a la soberanía. En 1986, la Suprema Corte de Justicia nulificó la disposición y en 1991 se incorporó a nivel constitucional la prohibición de nacionales. ${ }^{71}$ Sin embargo, en 1997 se volvió a reformar la Constitución para permitir la extradición de colombianos ${ }^{72}$ y en 1999 se entregó al primer colombiano después de nueve años que no ocurría. ${ }^{73}$

Respecto de este principio, la legislación mexicana lo recoge claramente y prescribe que ningún mexicano podrá ser entregado a un Estado extranjero sino en casos excepcionales, a juicio del Ejecutivo. ${ }^{74}$ No obstante, también señala que la calidad de mexicano no es obstáculo a la entrega del individuo reclamado cuando haya sido adquirida con posterioridad a los hechos que motiven la solicitud de extradición. ${ }^{75}$ La razón de

67 Francia, Grecia y Alemania. En último caso, la prohibición se encuentra a nivel constitucional. Artículo 16 (II), Ley Básica de la República Federal de Alemania (promulgada por el Consejo Parlamentario el 23 de mayo de 1949, y enmendada por el Tratado de Unificación del 31 de agosto de 1990 y el Estatuto Federal del 23 de septiembre de 1990.

68 Dinamarca, Finlandia, Islandia, Noruega y Suecia; Gilbert, op. cit., nota 2, p. 177.

69 No obstante, los párrafos 2 y 3 contemplan un periodo de cinco años durante el cual los Estados miembros podrán seguir rehusando la extradición con base en la nacionalidad del reclamado.

70 Nagle, Luz, The Rule of Law or the Rule of Fear: Some Thoughts on Colombian Extradition, 13 Loy. LA Int'1. \& Comp. LJ. 851, 1991.

71 Se menciona que ello fue producto de temor, intimidación y coerción proveniente de narcotraficantes colombianos. Warmund, Joshua, Comment: Removing Drug Lords and Street Pushers: The Extradition of Nationals in Colombia and the Dominican Republic, 22 Fordham Int'1. L.J. 2373 (1999), p. 2388.

72 Principalmente por presiones de EUA.

73 US Department of State, International Narcotics Control Strategy Report-March 2000, p. 121.

74 Artículo 14, Ley de Extradición Internacional [LEI].

75 Artículo 15, LEI. 
ello estriba en evitar que una persona eluda a la justicia extranjera y adquiera la nacionalidad mexicana como medio de protección frente a las autoridades extranjeras.

\section{LA EXTRADICIÓN EN MÉXICO ${ }^{76}$}

La legislación mexicana sobre extradición internacional dispone que la Secretaría de Relaciones Exteriores recibirá y examinará la petición formal de extradición y, en su caso, la admitirá. ${ }^{77}$ Los tribunales, después de oír la defensa del detenido, ${ }^{78}$ procede a emitir su opinión jurídica, ${ }^{79}$ y remite el expediente a dicha Secretaría. ${ }^{80}$ Es hasta entonces que el secretario de Relaciones Exteriores resuelve si concede o no la extradición, ${ }^{81}$ incluso si la opinión jurídica del tribunal fue en el sentido de que la extradición no debe proceder. La decisión de dicha Secretaría de extraditar al detenido sólo puede ser apelada mediante juicio de amparo. ${ }^{82}$

Así, el sistema de extradición mexicano puede considerarse uno en el que los fugitivos tienen doble oportunidad para intentar evitar ser extraditados. Los detenidos presentan sus argumentos en primera instancia ante los tribunales para que éstos emitan una "opinión" jurídica sobre el asunto. Dicha "opinión” puede ser revertida por la Secretaría de Relaciones Exteriores, pues sólo es una "opinión” que sirve para que la Secretaría tenga un panorama más claro sobre la situación jurídica propia del caso. Es hasta el momento en que el detenido apela mediante juicio de amparo la decisión de la Secretaría de conceder su extradición, que la resolución del juez ya no puede ser revertida por la autoridad administrativa y sólo puede ser modificada por una instancia judicial superior.

76 Para mayor precisión sobre el proceso de extradición en México, véase Gómez-Robledo Verduzco, Alonso, Extradición en derecho internacional, México, Universidad Nacional Autónoma de México, 2000; Colín Sánchez, Guillermo, Procedimientos para la extradición, México, Porrúa, 1993.

77 Artículo 19, LEI.

78 Artículo 25, LEI.

79 Artículos 27 y 28, LEI.

80 Artículo 29, LEI.

81 Artículo 30, LEI.

82 Artículo 33, LEI. 


\section{La extradición de nacionales en la práctica mexicana}

\section{La extradición de ciudadanos mexicanos hacia EUA, en específico} aquellos acusados de narcotráfico, ${ }^{83}$ ha sido durante mucho tiempo un motivo de tensiones en la relación bilateral México-EUA. ${ }^{84}$

La relación extraditoria entre ambos países no es un tema nuevo en la relación bilateral. El primer tratado de extradición México-EUA se suscribió el 11 de diciembre de $1861 .{ }^{85}$ Debido a los difíciles momentos que vivió México durante el siglo pasado con la intervención francesa, la guerra de reforma y diversos levantamientos, este tratado no tuvo gran vigencia ni aplicación. El tratado concluyó en 1899, cuando se firma el siguiente tratado de extradición.

El segundo Tratado de Extradición entró en vigor el 22 de abril de 1899. ${ }^{86}$ Fue modificado en tres ocasiones para incorporar nuevos delitos a los originalmente incluidos. En relación con nuestro tema, en $1925^{87}$ se

83 El título séptimo del Código Penal federal trata sobre los delitos contra la salud.

84 Labardini, Rodrigo, "Mexico Extradites to the US a Mexican National Charged With Drugtrafficking”, en 15 International Enforcement Law Reporter 193 (May 1999), pp. 193195 [en adelante Mexico Extradites Mexican National].

85 Fue suscrito por Sebastián Lerdo de Tejada, entonces diputado del Congreso de la Unión, y Tomás Corwin, enviado extraordinario y ministro plenipotenciario cerca del gobierno mexicano. El canje de los instrumentos de ratificación se llevó a cabo el 20 de mayo de 1862, con una modificación al artículo 3o. del propio convenio, y se promulgó tres días después. Puede consultarse en Tratados y Convenios de México, t. I: 1810-1883..., cit., nota 45, p. 305. Para la versión en inglés puede consultarse Moore, A Treatise on Extradition and International Rendition, pp. 1118-1121. El Convenio marca que las partes entregarán a la justicia a las personas acusadas de los crímenes extraditables cometidos dentro de la jurisdicción de parte demandada y que hayan buscado asilo o se encuentren dentro de los territorios de la otra. El tratado es interesante toda vez que en su artículo IV prescribe que la extradición sólo se hará por orden del Ejecutivo salvo en caso de crímenes cometidos en el territorio de los Estados o Territorios fronterizos, en cuyo caso podía ser ordenada "por la principal autoridad civil de ellos, ó por la principal autoridad civil ó judicial de los distritos ó partidos de los límites de la frontera, que para ese objeto pueda estar debidamente autorizada por la principal autoridad civil de los mismos Estados ó Territorios, ó cuando por alguna causa esté suspensa la autoridad civil del Estado ó Territorio, se podrá ordenar la extradición por el gefe (sic) superior militar que mande el mismo Estado o Territorio". El Convenio también excluyó expresamente la posibilidad de extraditar personas que hayan tenido la condición de esclavos en el lugar donde se cometió el delito, situación prohibida expresamente por la Constitución mexicana.

86 Fue firmado, en la ciudad de México el 22 de febrero de 1899, por Ignacio Mariscal, secretario de Relaciones Exteriores, y Powell Clayton, embajador extraordinario y plenipotenciario de EUA en México. El Senado de la República lo aprobó el 12 de abril y el canje de instrumentos de ratificación, previsto en su artículo XVIII, se efectuó el 22 de abril de 1899. Diario Oficial de la Federación: 25 de abril de 1899. Tratados y Convenios de México, t II: 1884-1899..., cit., nota 45, pp. 509-518. Para la versión en inglés puede consultarse Green Haywood Hackworth, Digest of International Law, parágrafo 318 , p. 59.

87 Celebrado por Manuel Téllez, embajador de México en Washington, y Frank B. Kellogg, secretario de Estado de EUA, en Washington, D. C., el 23 de diciembre de 1925. El Senado de la 
incorporaron los "delitos contra las leyes dictadas para la supresión del tráfico y del uso de narcóticos, manufactura ilícita o al tráfico de substancias nocivas a la salud, o productos químicos venenosos". ${ }^{88}$

El Tratado de Extradición actualmente en vigor fue suscrito el 4 de mayo de 1978 e inició su vigencia el 25 de enero de 1980 (en adelante, se le puede denominar TE-MX/EU). ${ }^{89}$ Este tratado es un documento comprehensivo. Consta de 23 artículos y un apéndice que enlista los delitos por los que se puede solicitar una extradición y que quedan cubiertos por el propio tratado. El tratado está diseñado para cubrir toda la materia de extradición, es decir, tanto la entrega de presuntos delincuentes como de personas ya sentenciadas.

El tratado describe la obligación de las partes de extraditar a personas reclamadas por la otra ${ }^{90}$ debido a delitos cometidos en el territorio de la requirente; ${ }^{91}$ sujeto a que se satisfaga el principio de doble criminalidad, ${ }^{92}$ define los procedimientos y requerimientos de probación para la extradición, ${ }^{93}$ incluye las excepciones en caso de delitos políticos y militares, ${ }^{94}$ permite exigir seguridades de que no se aplicará la pena capital, ${ }^{95}$ contempla el principio non bis in idem, ${ }^{96}$ fija la prescripción de la acción penal; 97 detalla el procedimiento de extradición, ${ }^{98}$ los documentos necesarios para que se pueda otorgar, ${ }^{99} \mathrm{y}$ la forma y condiciones para entregar al reclamado. ${ }^{100}$ En otras palabras, el tratado faculta a de cada una de las

República aprobó la modificación el 28 de diciembre de 1925. El canje de instrumentos se efectuó el 30 de junio de 1926. Diario Oficial de la Federación: 13 de agosto de 1926. Tratados y Convenios de México, t. V: 1924-1928..., cit., nota 45, pp. 245-248.

88 En 1902 se adicionó el delito de cohecho, Diario Oficial de la Federación, 13 de abril de 1903, Tratados y Convenios de México, t. III: 1900-1907..., cit., nota 45, pp. 61-63, y en 1941 se incorporó la participación "como cómplice o encubridor" de los diversos delitos extraditables, Diario Oficial de la Federación, 22 de marzo de 1941, Tratados y Convenios de México, t. VIII: 19381942..., cit., nota 45, pp. 571-574.

89 Diario Oficial de la Federación, 26 de febrero de 1980 y 16 de mayo de 1980. Tratados y Convenios de México, t. XXII: 1977-1978..., cit., nota 45, pp. 613-626.

90 Artículo 1o.

91 Artículo 2o.

92 Artículo 2.1.

93 Artículos 3o. y 12.

94 Artículo 5o.

95 Artículo 80.

96 Artículo 6o.

97 Artículo 7o.

98 Artículo 13.

99 Artículo 10.

100 Artículos 14 y 15. 
partes para resolver en forma autónoma sobre las solicitudes presentadas, y muestra que las partes, como entidades soberanas que son, preservan en sí mismas el derecho de libremente decidir sobre la suerte de los individuos residentes en su territorio, sean o no fugitivos de otros Estados.

El tratado fue ocasionalmente utilizado entre 1980 y $1994 .{ }^{101}$ En promedio, anualmente sólo se extraditó a un fugitivo hacia la contraparte. ${ }^{102}$ En este periodo, México entregó en extradición un total de ocho personas a EUA, y éste extraditó hacia México un total de 30 fugitivos. ${ }^{103}$ En consecuencia, las autoridades estadounidenses consideraban que la relación extraditoria en general resultaba insatisfactoria. ${ }^{104}$

El caso de José Luis del Toro, acusado del homicidio de una madre de seis niños en Miami, Florida, ejemplifica la irritación en EUA. Pese a que Del Toro fue entregado en extradición aproximadamente 18 meses después de que EUA presentó la petición formal de extradición, ${ }^{105}$ el caso tuvo una alta exposición pública y se encontraba en forma prominente en la escena política. El Congreso de EUA, particularmente el representante Dan Miller (R-FL), reiteradamente insistió en que Del Toro fuera entregado a EUA. En el Congreso se realizaron diversas audiencias públicas para discutir específicamente el caso, ${ }^{106} \mathrm{e}$ incluso se introdujeron iniciativas legislativas aludiendo al caso. ${ }^{107}$ Después de ser entregado a EUA, a Del Toro se le impusieron dos cadenas perpetuas consecutivas en Florida. ${ }^{108}$

Históricamente, México no había extraditado a sus nacionales, ${ }^{109}$ lo que frustraba notablemente a las autoridades estadounidenses de procuración de justicia. ${ }^{110}$ En este sentido, se ha señalado que durante la década

101 Son sintomáticos los comentarios del maestro Colín Sánchez, op. cit., nota 76, p. 371.

102 Juan Rebolledo, subsecretario para América del Norte y Europa de la Secretaría de Relaciones Exteriores, declaró que durante la década de 1980 sólo hubo una o dos extradiciones por año en ambos gobiernos. Carreño Figueras, José, "Diferencias de procedimiento y no de fines en el problema de las extradiciones con EU, dicen”, El Universal, ciudad de México, 16 de julio de 1999.

103 U. S.-Mexico 1995-2000, Main Results, nota 15, p. 8.

104 Weiner, Tim, "Mexico Agrees to Extradite Drug Suspect to California", The New York Times, 19 de enero de 2001, p. A5.

105 Lapso que puede considerarse rápido tomando en consideración los estándares mexicanos.

106 En especial Hearing Concerning Extradition Procedures between the United States and Mexico, Subcomm. on Crim. Justice, Drug Policy and Human Resources, Comm. on Gov. Reform, U. S. House of Representatives, 23 de junio de 1999. Rodrigo Labardini, Developments in U. S.-Mexico Extradition, en 16 International Enforcement Law Reporter 689 (April 2000), pp. 689-693.

107 H. Res. 381, 105th Congress, y S. Res. 171, 106th Congress.

108 Larose, Eric, Man Suspected of fleeing U. S.; Extradition from Mexico Sought, Milwaukee Journal Sentinel, 15 de enero de 2000, p. 3B.

109 Véase supra nota 11.

110 Nadelman, Ethan, Cops Across Borders, The Pennsylvania State University Press, University 
de 1980 México se mostraba tan paranoico frente a la posibilidad de intervención extranjera, que incluso protegía a sus criminales en el nombre de su soberanía. ${ }^{111}$ Asimismo, se consideraba que "jamás ha sido bien visto que el funcionario de un país entregue a sus nacionales para que éstos sean procesados por los funcionarios de otro o para que cumplan penas", 112 por lo que las autoridades mexicanas en forma regular solicitaban se negara la extradición de nacionales mexicanos. ${ }^{113}$

Esta "frustración" puede ser una de las explicaciones por las que EUA recurre al uso de métodos irregulares ${ }^{114}$ de extradición, a pesar de que los mismos representan una amenaza a la paz y seguridad internacionales. ${ }^{115}$ Uno de los casos más sonados en la relación bilateral ha sido el secuestro transfronterizo ${ }^{116}$ de Humberto Álvarez Macháin realizado en 1990 por agentes estadounidenses con el propósito de transportarle a EUA con el fin de que fuera juzgado por presuntos actos ilícitos cometi-

Park, Pennsylvania, 1993, p. 435, señala que ningún otro gobierno había frustrado tanto a las autoridades estadounidenses como el gobierno mexicano por su negativa a extraditar ciudadanos mexicanos.

111 “In the 1980's, Mexico was still so paranoid about foreign meddling that it protected even its criminals in the name of sovereignty", The Economist, 2 de febrero de 2001, p. 37.

112 Colín Sánchez, op. cit., nota 76, p. 365. Este autor agrega que "Esto no significa dejar impunes hechos ilícitos que deben ser sancionados, porque no debe olvidarse que en todos los lugares existen tribunales encargados de llevar a cabo esas funciones para que juzguen al sujeto de imputación en su propio país, enfatizando con ello un amplísimo margen de seguridad jurídica y confianza en los funcionarios y gobernantes del país, incluyendo su poder soberano". Idem.

113 Labardini, op. cit., nota 9, p. 31.

114 Se ha pretendido justificar la utilización de los métodos irregulares por "importantes problemas" con los tratados de extradición: vinculan sólo a las partes que los han ratificado, falta de uniformidad (en tratados, procedimientos y legislaciones), la entrega de personas sólo puede efectuarse cuando existe un tratado, dificultades asociadas a la sucesión de Estados, ruptura de relaciones diplomáticas, guerra, el dilema de mantener una red de tratados extraditorios, la necesidad de someter los tratados al órgano legislativo interno competente, defensas incluidas en los tratados limitando las posibilidades de lograr la extradición, desconfianza y desconocimiento de sistemas jurídicos y judiciales extranjeros, incluyendo la excepción del delito político. Entre otros, Yarnold, Barbara, International Fugitives. A New Role for The International Court of Justice, Nueva York, Praeger Publishers, 1991, pp. 13-18, Bassiouni, U. S. Law, cit., nota 42, pp. 167-180 y 217-219.

115 Con motivo del secuestro en 1960 de Adolf Eichmann (encargado de la expulsión forzada de judíos de Alemania, Austria y Checoeslovaquia, y en 1939 nombrado jefe de la sección de asuntos judíos de la Gestapo, encargado de "la solución final": la exterminación en masa de la población judía en los territorios ocupados) realizado en Argentina por Israel, el Consejo de Seguridad condenó la acción israelí pues se trataba de una acción que, al afectar la soberanía de un Estado miembro, causaba fricción internacional, y podía, si fuera repetido, hacer peligrar la paz y seguridad internacionales. U. N. Doc. S/P.V. 868 (1960). Sobre el caso Eichmann, véase Labardini, op. cit., nota 38 , pp. 388-392.

116 La práctica internacional es más frecuente de lo que podría uno suponer. Para una descripción de casi 40 casos internacionales, véase Labardini, op. cit., nota 38. 
dos en territorio mexicano. Con motivo del secuestro y la decisión de la Suprema Corte de Justicia de EUA convalidando el secuestro, ${ }^{117}$ México suspendió ${ }^{118}$ la cooperación antinarcóticos con EUA. ${ }^{119}$ Las tensiones generadas fueron de tal grado, que EUA hubo de iniciar inmediatamente negociaciones que condujeron al compromiso personal del presidente Bush ante el presidente Salinas de que su administración no alentaría ni permitiría estas prácticas en el futuro, ${ }^{120}$ y EUA hubo de suscribir un tratado para expresamente prohibir el secuestro transfronterizo. ${ }^{121}$

Adicionalmente, varios legisladores estadounidenses habían manifestado su pesar porque la extradición desde México tradicionalmente había sido deficiente. ${ }^{122}$ Por tal motivo, solicitaban incluso que se renegociara el Tratado de Extradición Bilateral, ${ }^{123}$ debido a que México sólo cumplía con el $65 \%$ de las solicitudes de extradición presentadas por EUA. ${ }^{124}$ En otras instancias, incluso se manifestó que México debía demostrar un cla-

117 El 15 de junio de 1992, la Suprema Corte de Justicia de EUA dio a conocer su decisión United States v. Álvarez Macháin, 112 S. Ct. 2188 (1992), convalidando el secuestro transfronterizo debido a que el Tratado de Extradición México-EUA no prohíbe expresamente dicho acto ni contempla acciones a tomar en caso que se lleven a cabo. Para un detallado análisis de todo el caso, incluido el secuestro y sus implicaciones, incluidas las derivadas de la referida sentencia, véase Labardini, op. cit., nota 9 .

118 Adicionalmente, el artículo 123 del Código Penal federal fue reformado en julio de 1992 para incluir como traición a la patria "al que prive ilegalmente de su libertad a una persona en el territorio nacional para entregarla a las autoridades de otro país o trasladarla fuera de México con tal propósito".

119 Al conocerse la sentencia Álvarez Macháin, cit., nota 117, México anunció el mismo 15 de junio de 1992 la suspensión temporal de las actividades de la DEA hasta no recibir garantías suficientes de que no se repetirían los hechos. SRE, Boletín de Prensa núm. B-1122, 15 de junio de 1992, reproducido en Límites II..., cit., nota 36, pp. 111-114. Sin embargo, la cooperación antinarcóticos fue restablecida al día siguiente para no dar pauta a una señal equivocada a los narcotraficantes, SRE, Boletín de Prensa núm. B-1126, 16 de junio de 1992, reproducido en Límites II..., cit., nota 36, pp. 117 y 118, y después de que EUA acordó revisar el Tratado de Extradición de 1978. Rozental, Andrés, La política exterior de México en la era de la modernidad, México, Fondo de Cultura Económica, 1993, p. 75.

120 Kreczko, Alan (consultor jurídico adjunto, Depto. de Estado de EUA), Declaración ante el Subcomité sobre Derechos Civiles y Constitucionales, Washington, D. C., Comité Judicial de la Cámara de Representantes, 24 de julio de 1992; y Depto. de Estado de EUA, Boletín de Prensa, 3 de agosto de 1992, vol. 3, núm. 31, p. 614 (3).

121 Para un análisis del mismo y su texto, véase Labardini, Rodrigo, "El Tratado entre México y Estados Unidos de América para Prohibir los Secuestros Transfronterizos”, Revista Mexicana de Procuración de Justicia, México, Procuraduría General de Justicia del Distrito Federal, vol. I, núm. 5, junio de 1997, pp. 79-94.

122 H. J. Res. 58, 105th Congress, 1st session, H. Res. 95, 105th Congress, 1st session, S. J. Res. 19, 105th Congress, 1st session, S. J. Res. 20, 105th Congress, 1st session.

123 H. Res. 381, 105th Congress, 1st session, y S. Res. 171, 106th Congress, 1st session.

124 H. J. Res. 61, 106th Congress, 1st session. 
ro progreso "arrestando y extraditando a importantes narcotraficantes" 125 para ser "certificado" en su cooperación antinarcóticos. ${ }^{126}$

Por estos motivos, es fácil comprender por qué a partir de 1995 la decisión de revisar la política extraditoria y, en particular, autorizar la extradición de nacionales y su entrega efectiva hacia EUA, se ofrecerían como pruebas de la voluntad del gobierno de México para combatir al narcotráfico. ${ }^{127}$

Durante 1995, el gobierno mexicano llevó a cabo una importante revisión de su política extraditoria. ${ }^{128}$ Esta revisión y la labor desarrollada por las autoridades de ambos países ${ }^{129}$ han incrementado el entendimiento mutuo sobre el sistema jurídico de la contraparte, y han logrado agilizar los mecanismos para procesar las solicitudes de extradición. Esto ha derivado en un notable progreso en los últimos seis años de vigencia del Tratado de Extradición de 1978.

En contraste con el periodo 1980-1994, de 1995 a la fecha, en promedio se han procesado anualmente más de 20 solicitudes de extradición. ${ }^{130}$ Durante 1997, 1998 y 1999, EUA solicitó a México a 144 personas en extradición, y México presentó 106 solicitudes. ${ }^{131}$ Durante 2000, México entregó 10 fugitivos a EUA, ${ }^{132}$ y EUA entregó $15 .{ }^{133}$ En el periodo

125 S. Con. Res. 10, 105th Congress, 1st session.

126 Véase supra nota 25.

127 Cfr. Labardini, Mexico Extradites Mexican National..., cit., nota 84. Adicionalmente, los tribunales estadounidenses consideraban que México había manifestado su renuencia a extraditar a nacionales en casos que no fueron de gravedad. County of Orange v. Ranger Ins. Co., 61 Cal. App. 4th 795, 71 Cal. Rptr. 2d 811 (4th Dist. 1998), Review denied, (Apr. 29, 1998).

128 Mexico's Fight Against Drugs1999..., cit., nota 11, pp. 48-51.

129 El trabajo se ha desarrollado principalmente a través del Grupo Plenario de Procuración de Justicia México-EUA (GPPJ) (en inglés: Mexico-U. S. Senior Law Enforcement Plenary (SLEP)), bajo al dirección del Grupo de Contacto de Alto Nivel Contra las Drogas México-EUA (GCAN). El GCAN fue creado en marzo de 1996, y funge como el foro bilateral de mayor importancia en donde funcionarios de alto nivel se reúnen y analizan actividades antinarcóticos y otros temas de procuración de justicia. Es co-presidido por el Director de la Oficina para la Política Nacional de Control de Drogas de la Casa Blanca (ONDCP), el secretario de Relaciones Exteriores de México y el procurador general de la República (PGR). Se ha reunido en nueve ocasiones (ocho de ellas en sesión plenaria). Después del GCAN, el GPPJ es el grupo de mayor contacto en el ámbito de cooperación México-EUA contra actividades delictivas. GPPJ es coordinado por los procuradores generales de ambos Estados. Su función principal es definir las estrategias básicas para facilitar el intercambio de información y la cooperación jurídica en materia de procuración de justicia, incluyendo tráfico de drogas ilícitas.

130 Carreño, supra nota 102 (se cita al subsecretario Rebolledo).

131 Mexico's Fight Against Drugs-1999..., cit., nota 11, pp. 48-49.

132 Incluyendo a un mexicano (Alejandro Velásquez Ruanova) por narcotráfico (distribución de cocaína). Véase Procuraduría General de la República, Boletín de Prensa 290/00, ciudad de México, 7 de junio de 2000 .

133 La mayoría acusados de homicidio. 
1995-2000, México extraditó un total de 61 individuos hacia EUA, y EUA entregó un total de 86. Esto es, en cinco años, el número de personas entregadas por México, comparado con los quince años anteriores, creció siete veces, en tanto que el número de personas entregadas por EUA se triplicó. ${ }^{134}$

Adicionalmente, debido a que la expulsión (o deportación) frecuentemente es más rápida y menos intensiva en uso de recursos que la extradición, México y EUA formalmente desarrollaron el Programa de Identificación y Alerta de Fugitivos durante 1996-1997. ${ }^{135}$ El programa está diseñado para facilitar el intercambio de información sobre fugitivos de cada país que se hayan dado a la fuga o estén residiendo en otro país en violación con la legislación migratoria del país donde se encuentran. El mecanismo funcionó muy bien hasta 1998, ${ }^{136}$ enfrentó algunos problemas en $1999,{ }^{137}$ pero parece haberse normalizado una vez más. ${ }^{138}$

\section{U. S.-Mexico 1995-2000, Main Results..., cit., nota 15, p. 8.}

135 Un ejemplo lo constituye la expulsión desde México hacia EUA de Ernesto Martínez López. Martínez, quien se fugó hace más de 30 años de una prisión en Texas, donde compurgaba una cadena perpetua por el homicidio de una niña de 12 años y lesiones a un infante hermano de dicha niña, no podía ser extraditado debido a que había prescrito la causa. Martínez fue expulsado de México por violación a la legislación migratoria. White House Office for the National Drug Control Policy (ONDCP), U. S.-Mexico Counterdrug Cooperation, Sep. 15, 1997, Chapter V, Extradition [en adelante U. S.-Mexico Counterdrug Coop.].

136 Diez fugitivos fueron expulsados desde México en el primer semestre de 1997. U. S.-Mexico Counterdrug Coop..., cit., nota 135. En lo que se consideró como "un año muy exitoso para México", el programa logró durante 1998 la identificación, localización y expulsión de más de 30 ciudadanos estadounidenses que se habían fugado. Lee Warren, Mary (subprocuradora general asistente), Statement before the Subcomm. on Crim. Justice, Drug Policy and Human Resources, Concerning the Importance of Extradition in International Crime Control, Comm. on Gov. Reform, U. S. House of Representatives, May 13, 1999 [en adelante Importance of Extradition]).

137 Lee Warren, Mary (subprocuradora general asistente), Statement before the Subcomm. on Crim. Justice, Drug Policy and Human Resources, Concerning Extradition Procedures between the United States and Mexico, Comm. on Gov. Reform, U. S. House of Representatives, June 23, 1999 (declarando que durante el primer semestre de 1999 se había registrado una importante disminución en el número de entregas desde México).

138 Tres personas fueron expulsadas desde México el 1o. de septiembre de 1999. Mexico's Fight Against Drugs-1999..., cit., nota 11, p. 53. El 20 de junio de 2001, Ernesto Díaz Infante, ex-ministro de la SCJN, fue deportado de EUA hacia México. Díaz Infante era buscado como probable responsable en la comisión de los delitos de cohecho y contra la administración de la justicia, acusado de recibir 500 mil dólares para interceder a favor de Alejandro Braun Díaz, alias "El Chacal”, a quien se responsabilizaba de secuestrar, violar y asesinar a una niña de seis años de edad. México presentó a EUA la correspondiente solicitud de extradición en 1994. Díaz Infante ingresó a EUA de manera legal (incluso contaba con licencia de conducir). Sin embargo, fue detenido por el Servicio de Migración y Naturalización (INS) por estar viviendo en San Antonio, Texas, de manera ilegal. Hernández Elías, Vicente, "Extraditan a México a un ex ministro de la SCJN", Milenio Diario, 21 de junio de 2001, p. 14. El caso más reciente en que México entregó a un fugitivo estadounidense es el de Daniel Escobedo, quien se encontraba en la lista de los 15 fugitivos más buscados por el servicio de alguacil 
La extradición de nacionales mexicanos ejemplifica con claridad el cambio en las políticas y prácticas extraditorias mexicanas. ${ }^{139}$ La extradición de cualquier fugitivo es una facultad discrecional para los Estados. ${ }^{140}$ Contrario a lo que ocurre en otros países, en México ni la Constitución ni la legislación secundaria prohíben la extradición de ciudadanos mexicanos. ${ }^{141}$ Sin embargo, si bien el Poder Ejecutivo se encuentra facultado para conceder su extradición, sólo puede hacerlo en casos excepcionales. ${ }^{142}$ En concordancia con lo anterior, el Tratado de Extradición México-EUA dispone que "Ninguna de las dos partes contratantes estará obligada a entregar a sus nacionales pero el Poder Ejecutivo de la parte requerida tendrá la facultad, si no se lo impiden sus leyes, de entregarlos si, a su entera discreción, lo estima procedente". ${ }^{143}$

Antes de 1995, ningún mexicano había sido extraditado. ${ }^{144}$ No obstante, no se contemplaba un espacio de impunidad ya que el Tratado de Extradición contempla que si la solicitud es negada con fundamento en la nacionalidad del individuo, la parte requerida debe someter el caso a sus autoridades competentes para el ejercicio de la acción penal, siempre que la parte requerida tenga jurisdicción ${ }^{145}$ para perseguir el delito. ${ }^{146}$

de EUA (U. S. Marshalls). Procuraduría General de la República, Boletín de Prensa 424/01, 21 de junio de 2001.

139 Labardini, Court Allows Extradition of Nationals, supra nota 24.

140 La extradición es considerada un acto de soberanía. Bassiouni, U. S. Law..., cit., nota 42, p. 1.

141 Como observamos en el apartado previo, muchos países tienen prohibido en su Constitución o en su legislación interna la extradición de sus nacionales, o bien lo realizan como una política pública. Por ejemplo, Francia, Alemania, Austria, Bélgica, Eslovenia, Brasil, Ecuador, Panamá y Venezuela. Adicionalmente véase Borek, op. cit., nota 50.

142 "Ningún mexicano podrá ser entregado a un Estado extranjero sino en casos excepcionales a juicio del Ejecutivo", artículo 14, Ley de Extradición Internacional.

143 Artículo 9.1.

144 Mexico's Fight Against Drugs-1999..., cit., nota 11, p. 49.

145 De acuerdo con Fernando Flores García, si bien en derecho común (common-law) los términos "jurisdicción" y "competencia" llegan a confundirse, ambos conceptos se distinguen: jurisdicción es "el campo o esfera de acción o de eficacia de los actos de una autoridad"; en tanto que competencia alude a una "idoneidad atribuida a un órgano de autoridad para conocer o llever a cabo determinadas funciones o actos jurídicos". Instituto de Investigaciones Jurídicas, Diccionario jurídico mexicano, 2a. ed., México, Porrúa-UNAM, 1997, ts. III (I-O) y I (A-CH), pp. 1884 y 542, respectivamente.

146 Artículo 9.2. 
Con este propósito, las autoridades mexicanas recurrían al artículo 4o., CPF, para establecer jurisdicción sobre el inculpado y poderlo juzgar en México de conformidad con la legislación mexicana por un presunto delito cometido en el exterior. ${ }^{147}$ De hecho, el artículo 4o., CPF, es utilizado por las autoridades mexicanas, cuando por una u otra razón la extradición de un fugitivo no puede llevarse a cabo. La importancia de este recurso se advierte cuando observamos que entre 1993 y 1999, las autoridades estadounidenses solicitaron la detención de 432 individuos, de los cuales 228 fueron localizados y 188 finalmente fueron sentenciados en México. ${ }^{148}$

Como indicamos, las autoridades mexicanas revisaron la política de extradición de nacionales mexicanos. En el marco jurídico-institucional desarrollado bilateralmente para la cooperación contra el crimen, ${ }^{149}$ México definió a la cooperación internacional como una prioridad en la lucha contra el crimen, especialmente si estaba relacionado con el narcotráfico. En consecuencia, y con el propósito de reducir la impunidad, modificó su política y práctica ${ }^{150}$ al estimar que había llegado el momento de utilizar en toda su extensión las disposiciones jurídicas que permitían la extradición bajo casos excepcionales, permitiendo con ello que los mexicanos pudieran enfrentarse a acciones penales en su contra en el lugar donde presuntamente cometieron los delitos.

Desde 1995, México ha entregado en extradición a EUA a 16 mexica-

147 "Los delitos cometidos en territorio extranjero por un mexicano contra mexicanos o contra extranjeros, o por un extranjero contra mexicanos, serán penados en la república, con arreglo a las leyes federales, si concurren los requisitos siguientes: I. Que el acusado se encuentre en la república; II. Que el reo no haya sido definitivamente juzgado en el país en que delinquió, y III. Que la infracción de que se le acuse tenga el carácter de delito en el país en que se ejecutó y en la república”.

148 Fuentes, Víctor, "Queda abierta puerta para extraditables”, Reforma, ciudad de México, 19 de enero de 2001.

149 En ese entonces, el marco jurídico de la cooperación internacional México-EUA incluía diversos tratados, acuerdos, memoranda de entendimiento y notas diplomáticas en las siguientes áreas: ejecución de sentencias penales (1976), extradición (1978), recuperación y devolución de vehículos y aeronaves robadas (1981), asistencia jurídica mutua (1987), cooperación contra el narcotráfico (1989), prohibición de secuestros transfronterizos (1994) y combate de actividades financieras ilícitas (1995). Posteriormente, nuevos instrumentos internacionales han sido acordados y entrado en vigor: compartición de bienes decomisados fruto de narcotráfico (1995), extradición temporal (1998), carta entre procuradores generales y memorándum de entendimiento sobre actividades de procuración de justicia (1998 y 1999, respectivamente), intercambio de información sobre efectivo e instrumentos monetarios (2000), asistencia mutua entre administraciones de aduanas (2000), y cooperación para el control de precursores químicos (2000). Adicionalmente, ambos países publicaron un diagnóstico conjunto sobre la amenaza de las drogas ilícitas (1997), adoptaron una Alianza contra las Drogas (1997), una estrategia bilateral contra las drogas (1998), medidas de efectividad de dicha estrategia (1999) y emitieron un informe sobre el estado en que se encontraban dichas medidas (2000).

150 Mexico's Fight Against Drugs-1999..., cit., nota 11, p. 49. 
nos. ${ }^{151}$ Adicionalmente, 14 ciudadanos mexicanos ${ }^{152}$ han iniciado juicios de amparo apelando las órdenes de extradición emitidas por la Secretaría de Relaciones Exteriores. Debemos señalar que en el mismo periodo 19952000, EUA extraditó aproximadamente al mismo número de estadounidenses hacia México. ${ }^{153}$

Pese a la revisión realizada por las autoridades mexicanas, y aún cuando se hayan extraditado a mexicanos, debe subrayarse que ello no garantiza que México habrá siempre de extraditar a ciudadanos mexicanos. La legislación contempla esta posibilidad en "casos excepcionales" 154 y el Tratado de Extradición expresamente no obliga a las partes a entregar a sus nacionales, dejándolo al criterio de la parte requerida. ${ }^{155}$ Más importante aún, la extradición es un acto soberano. ${ }^{156}$

El 7 de febrero de 1999, ${ }^{157}$ la Secretaría de Relaciones Exteriores negó la solicitud estadounidense para extraditar a cinco mexicanos acusados de lavado de dinero. ${ }^{158}$ No obstante, y de conformidad con el Tratado de Extradición, ${ }^{159}$ los cinco fueron juzgados en México por los delitos de que se les acusó. ${ }^{160}$ Los cinco casos estaban directamente relacionados con la "Operación Casablanca" ${ }^{161} \mathrm{El}$ interés mexicano por las activida-

151 Tres de ellos naturalizados, Mexico's Fight Against Drugs-1999..., cit., nota 11, p. 50; y dos extraditados con entrega diferida, véase supra nota 15 . Asimismo, algunos de ellos no apelaron las decisiones de extraditarlos o consintieron a ser extraditados. Associated Press, Mexico says it is ready to extradite 14 suspects to the United States, 20 de enero de 2001. Asimismo véase Labardini, Mexico Extradites Mexican National..., cit., nota 84, detallando que Tirso Ángel Robles, entregado el 23 de marzo de 1999 a EUA, fue el primer nacional mexicano sin doble nacionalidad y quien apeló el proceso de extradición.

152 Procuraduría General de la República, Boletín de Prensa 026/01, 19 de enero de 2001.

153 Fueron 12 estadounidenses los extraditados hacia México. U. S.-Mexico 1995-2000 Main Results..., cit., nota 103, p. 8 .

154 Artículo 14, Ley de Extradición Internacional.

155 Artículo 9o. (2).

156 Bassiouni, International Extradition..., cit., nota 140, p. 1.

157 Véase Embajada de México en Estados Unidos de América, "Government of Mexico Announces Decisions on 'Operation Casablanca'”, Boletín de Prensa, Bol-99-17, 7 de febrero de 1999, y Secretaría de Relaciones Exteriores, "Comunicado Conjunto de la Secretaría de Relaciones Exteriores y la Procuraduría General de la República”, Boletín de Prensa B-048, 7 de febrero de 1999.

158 Gildardo Martínez López, Carlos Escoto Alcalá, Miguel Ángel Barba Martín, Jorge Milton Díaz, José Sergio Calderón Fernández. Todos fueron provisionalmente detenidos el 19 de agosto de 1998 con vistas a su posible extradición internacional hacia EUA. Mexico's Fight Against Drugs1998..., cit., nota 11, p. 57.

159 Artículo 9o. (2).

160 Véanse los boletines de prensa mencionados supra nota 157.

161 En mayo de 1998, el Servicio de Aduanas de EUA concluyó la "Operación Casablanca", referida por EUA como la investigación de lavado de dinero más grande y más comprehensiva en la historia estadounidense de procuración de justicia. Como parte de la investigación, agentes estadounidenses ingresaron a territorio mexicano y sin informar ni notificar a las autoridades mexicanas reali- 
des encubiertas realizadas por agentes estadounidenses durante el curso de la "Operación Casablanca" generó una investigación mexicana para definir si dichos agentes habían violado o no la legislación mexicana. México anunció el 7 de febrero de 1999, que no hubo violación técnica de la legislación mexicana, pero reafirmó que dichas actividades realizadas por agentes extranjeros resultaban inaceptables. ${ }^{162}$ Seguramente el hecho de que los casos estuvieran directamente relacionados con la "Operación Casablanca" fue un importante factor que el gobierno mexicano tomó en consideración al negar las solicitudes. Adicionalmente, el gobierno de EUA no criticó en forma importante la expresada negativa, presumiblemente como una forma de tranquilizar la preocupación mexicana después de la "Operación Casablanca". ${ }^{163}$

En 1999 concluyeron tres juicios de amparo impugnando la extradición de mexicanos acusados en EUA por narcotráfico. En los tres casos esencialmente se arguyeron las mismas disposiciones normativas, pero con resultados contradictorios, mostrando con ello las dificultades interpretativas del tema.

En dos de ellos, ${ }^{164}$ los tribunales colegiados rechazaron su extradición indicando que el artículo 4o., CPF, era imperativo, y que los "casos excepcionales" del artículo 14o., LEI, sólo podían aplicarse cuando no había un tratado bilateral en vigor, por lo que todo mexicano inculpado de delitos en el exterior debía ser procesado en México.

zaron operaciones encubiertas, durante las cuales presumiblemente cometieron diversos ilícitos en México. La investigación de tres años resultó en el aseguramiento de aproximadamente 100 millones de dólares en frutos de drogas ilícitas, el arresto de 168 individuos y la investigación de 14 bancos de México y Venezuela. El 30 de marzo de 1999, dos instituciones bancarias mexicanas se declararon culpables de lavado de dinero realizado por empleados de relativo bajo nivel. Véase Laundering 'milestone' reached as two Mexican banks convicted, Money Laundering Alert, May 1999. México protestó la "Operación Casablanca" por el uso unilateral de actividades, limitaciones a la cooperación bilateral anticrimen y la seria violación de su soberanía nacional.

162 Véanse los boletines de prensa mencionados supra nota 157.

163 Ambos países llegaron incluso a celebrar un intercambio de cartas (el 2 de julio de 1998) entre sus procuradores generales y posteriormente un Memorándum de Entendimiento sobre Procedimientos en Materia de Procuración de Justicia (durante la visita del presidente Clinton a Mérida el 15 de febrero de 1999), con el propósito de notificarse mutuamente sobre cualquier acción de procuración de justicia o de investigación que pudiera tener efectos en el otro país.

164 Malherbe de León, Óscar y González Castro, Jaime, U. S. Department of State, International Narcotics Control Strategy Report-March 1999 [en adelante INCSR-1999], p. 172. Cfr. Medina, María Elena, "Denuncian retroceso en extradiciones", Reforma, ciudad de México, 3 de marzo de 1999, p. $12 \mathrm{~A}$. 
Con el propósito de resolver en forma definitiva la autorización de la extradición de mexicanos, la Secretaría de Relaciones Exteriores y la Procuraduría General de la República solicitaron ante la SCJN la revisión del amparo utilizando un tercer caso. ${ }^{165} \mathrm{El}$ máximo tribunal rechazó la solicitud al resolver que la materia no era de naturaleza constitucional y que aún no se observaba un conflicto de decisiones entre distritos judiciales. ${ }^{166}$ En consecuencia, el tema continuó siendo de interpretación judicial, y permaneció como elemento irritante en la relación bilateral debido a que los procesos jurídicos avanzaban lentamente en los tribunales, y sobre todo porque los resultados iniciales habían sido contrarios a lo esperado por ambos gobiernos.

En un tercer caso, ${ }^{167}$ y en clara contradicción con los otros dos casos, se aceptó la extradición de un ciudadano mexicano ${ }^{168}$ por considerar que la facultad del Ejecutivo no se encontraba limitada por la Constitución ni por el artículo 4o., CPF. ${ }^{169}$ En vista de lo anterior, el propio tribunal colegiado remitió el asunto a la SCJN, debido a que existía una contradicción de tesis entre distritos judiciales sobre un mismo punto jurídico. ${ }^{170}$

165 Everardo Arturo “Kitty” Páez. Véase Fuentes, Víctor, "Pide la PGR puntualizar posición de SCJN sobre las extradiciones", El Financiero, 3 de marzo de 1999, p. 41; "Piden a SCJN resolver caso de extradiciones", Infosel Financiero, ciudad de México, 25 de febrero de 1999; y Warren, Importance of Extradition..., cit., nota 136.

166 Suprema Corte de Justicia de la Nación, Boletín de Prensa 172, ciudad de México, 21 de abril de 1999; "Niega SCJN a PGR revisión de amparo a narcotraficantes", Infosel Financiero, ciudad de México, 23 de abril de 1999; y Warren, Importance of Extradition..., cit., nota 136.

167 Everardo Arturo "Kitty" Páez. Véase "Piden a SCJN resolver caso de extradiciones", Infosel Financiero, ciudad de México, 25 de febrero de 1999, y Warren, Importance of Extradition..., cit., nota 136; así como Warren, Mary Lee (subprocuradora general asistente), Hearing of the Criminal Justice, Drug Policy and Human Resources Subcommittee of the House Government Reform Committee on U. S.-Mexico Extradition Procedures, U. S. House of Representatives, 23 de junio de 1999, transcripción por Federal News Service.

168 Sin doble nacionalidad. Anteriormente se había extraditado a extranjeros que también poseían la calidad de mexicanos. Véase Labardini, Mexico Extradites Mexican National..., cit., nota 84; id., Mexico Extradites Major Drug-Trafficker to the U. S. and Recent Developments in U. S.-Mexico Extradition, en 15 International Enforcement Law Reporter 315 (August 1999), pp. 315319; y Mexico's Fight Against Drugs-1998..., cit., nota 11, p. 57. Por lo menos en una ocasión, la doble nacionalidad facilitó a las autoridades mexicanas la posibilidad de extraditar al fugitivo. Cfr. Secretaría de Relaciones Exteriores, Boletín de Prensa B-130, 26 de abril de 1996; y Zagaris, Bruce, Mexico Extradites Two Nationals to the U. S., 12 International Enforcement Law Reporter 220-221 (June 1996).

169 Warren, Importance of Extradition..., cit., nota 136.

170 Una vez concluidas las etapas del procedimiento respectivo, el 4 de mayo de 1998 la Secretaría de Relaciones Exteriores (SRE) concedió la extradición de Páez, a pesar de que el juez sexto de Distrito en Materia Penal en el Distrito Federal había opinado que ésta no era procedente en razón de que Páez Martínez es de nacionalidad mexicana (para una somera descripción del proceso de extradición en México véanse supra notas 76-81). La resolución de la Cancillería fue exitosamente combatida mediante juicio de amparo 293/98, en el cual el 25 de noviembre de 1998, el juez segundo de Distri- 
Es menester mencionar que no existe una definición ni precisión alguna sobre el concepto de "casos excepcionales". Podemos apuntar que los delitos relacionados con narcotráfico aparentemente quedan comprendidos en el concepto. ${ }^{171}$ Esto incluye la presunta pertenencia a una organización criminal y la participación en el tráfico de más de 1.4 toneladas de cocaína. ${ }^{172}$ De igual forma, pueden quedar comprendidos los casos en que por el principio general de derecho penal non bis in idem $^{173}$ algunos hechos delictivos pudieran quedar impunes, ${ }^{174} \mathrm{y}$, al menos en forma conjunta, ${ }^{175}$ la naturaleza "oprobiosa" de los delitos imputados, los casos de doble nacionalidad y las situaciones en que la extrema gravedad de los delitos afectan de manera importante valores fundamentales de la sociedad en su conjunto. ${ }^{176}$

to en Materias de Amparo y Juicios Civiles Federales (Toluca, Estado de México) consideró que el artículo 4o., CPF, prohíbe la extradición de mexicanos. Tanto SRE como el Ministerio Público de la Federación interpusieron recurso de revisión que fue resuelto por el Segundo Tribunal Colegiado en Materia Penal del Segundo Circuito el 10 de junio de 1999, en el sentido de que por tratarse de un nacional mexicano, la Cancillería debía emitir una nueva resolución debidamente motivada en cuanto a que se trataba de un caso excepcional. Sin embargo, con motivo del análisis de la resolución del juez de Distrito, el Tribunal Colegiado denunció contradicción de tesis ante la Suprema Corte de la Justicia de la Nación, porque en su concepto el artículo 4o., CPF, no prohíbe la extradición de mexicanos. Procuraduría General de la República, Boletín de Prensa 287/01, 4 de mayo de 2001.

171 Cfr. Mexico's Fight Against Drugs-1999..., cit., nota 11, pp. 48-51.

172 Se ha citado a la Secretaría de Relaciones Exteriores, indicando que durante varios años, Páez formó parte de una organización criminal internacional dedicada al tráfico ilícito de drogas, que reclutó personas para la banda comandada por Benjamín Arellano Félix, que lo hizo de manera reiterada y que en los hechos que se le atribuyen están involucrados más de mil cuatrocientos kilogramos de cocaína, "circunstancias que en sí mismas expresan la gravedad del caso expuesto en la solicitud del gobierno de Estados Unidos de América, respecto de Everardo Arturo Páez, y que justifican por sí sola plenamente la decisión que se toma en el presente Acuerdo". González, María de la Luz, "Justifican extradición de narcotraficante", Reforma, 15 de enero de 2000.

173 Consagrado en el artículo 23 constitucional y el artículo 6o. del Tratado de Extradición México-EUA.

174 Francisco Gámez García, ciudadano mexicano (Mexico's Fight Against Drugs-1999..., cit., nota 11, p. 50), fue entregado a EUA porque "no podía ser procesado en México en los términos del artículo 4o. del Código Penal federal porque ya había sido juzgado en Arizona, EUA", Secretaría de Relaciones Exteriores, Boletín de Prensa B-130, 26 de abril de 1996. Gámez no interpuso juicio de amparo y fue entregado el 17 de abril de 1996. Idem.

175 Secretaría de Relaciones Exteriores, Boletín de Prensa B-130, 26 de abril de 1996.

176 La Secretaría de Relaciones Exteriores resolvió conceder la extradición de Aarón Morel Lebaron, ciudadano mexicano (Mexico's Fight Against Drugs-1999..., supra nota 11, p. 50), "tomando en consideración la naturaleza oprobiosa de los delitos que se le atribuyen, su extrema gravedad que afectan de manera importante valores fundamentales de la sociedad en su conjunto; así como el hecho de que el gobierno estadounidense le atribuye su nacionalidad, toda vez que tanto el padre como la madre del requerido eran nacionales estadunidenses". Secretaría de Relaciones Exteriores, Boletín de Prensa B-130, 26 de abril de 1996. Morel no interpuso juicio de amparo y fue entregado el 25 de abril de 1996. Idem. 
Por el contrario, como vimos, en ocasiones el lavado de dinero puede no ser elemento suficiente para extraditar a un fugitivo, en especial si han ocurrido actos que violentan la legislación y soberanía nacionales. ${ }^{177}$

Puede llegar a estimarse que podría ser útil contar con una precisión del concepto "casos excepcionales" y definir en qué circunstancias podría concederse la extradición de mexicanos, lo que permitiría a la población mexicana (que es quien podría resultar agraviada) ${ }^{178}$ conociera estas posibilidades de antemano. Sin embargo, deben tomarse en cuenta las siguientes consideraciones. Quienes podrían quedar sujetos a extradición, en principio han delinquido o se han dado a la fuga de otras jurisdicciones ${ }^{179} \mathrm{y}$ en principio debieran ser juzgados en las jurisdicciones donde delinquieron. ${ }^{180}$ Adicionalmente, definir los "casos excepcionales" podría atar al concepto y heer rígida su aplicación, lo que atentaría contra el concepto mismo. ${ }^{181}$ Es decir, definir un caso excepcional en forma general puede limitar su aplicación futura pues sólo aquellos procesos que exactamente se ajusten a lo contemplado quedarían incluidos, y concomitantemente restarían la discrecionalidad que la propia Ley de Extradición Internacional concede al Poder Ejecutivo.

Así, resulta difícil e impráctico intentar definir a priori cuándo un caso podría resultar "excepcional". Lo que sí, debe exigirse que la autoridad debidamente funde y motive casuísticamente los "casos excepcionales".

177 Como la "Operación Casablanca”. Cfr. supra notas 157-163.

178 Y que junto con los intereses mexicanos deben proteger las autoridades mexicanas.

179 Ello no significa que las autoridades puedan abandonarle, incluso en el exterior. Una función básica de los miembros del servicio exterior mexicano es proporcionar protección a los connacionales que se encuentren en el extranjero y que la necesiten por cualquier motivo. La Ley del Servicio Exterior Mexicano y su Reglamento, respectivamente, artículos 2 (II) y 44 (I), Diario Oficial de la Federación, 4 de enero de 1994, y artículo 53, Diario Oficial de la Federación, 11 de octubre de 1994, marcan que, de conformidad con los principios y normas del derecho internacional, es una obligación prioritaria de los miembros del servicio exterior proteger los intereses de los mexicanos en el extranjero. Con estos fines deben presentar sus buenos oficios, impartir asistencia y protección consular, y, llegado el caso, proporcionar a la Secretaría de Relaciones Exteriores información para que ésta decida si se ejerce la protección diplomática.

180 En esencia, al igual que en un caso de extradición entre los estados de la Federación. Asimismo, véase Millares, Alfonso, "Procede la extradición de mexicanos a EU si delinquieron allá: Suprema Corte", Excélsior, 19 de enero de 2001, primera plana.

181 No obstante, serían recomendables unos lineamientos a manera de simple orientación y guía y no como una definición limitativa de los casos en que pudiera contemplarse que se está frente a "casos excepcionales". 


\section{La contradicción de tesis}

El Primer Distrito ${ }^{182}$ resolvió que el Poder Ejecutivo federal no se encuentra obligado a entregar a nacionales mexicanos porque, no obstante que se encuentra autorizado para discrecionalmente entregar a un nacional en extradición, dichas facultades se encontraban limitadas por el artículo 4o., CPF, obstaculizando por tanto al Poder Ejecutivo federal dicha extradición. Por su parte, el Segundo Distrito ${ }^{183}$ resolvió que la entrega de nacionales mexicanos solicitados en extradición por EUA es una facultad discrecional del Poder Ejecutivo federal, y no podía, por tanto, argüirse que el artículo 4o., CPF, constituía un impedimento a la extradición del fugitivo.

Como puede desprenderse, la resolución de la SCJN era ansiosamente esperada por las comunidades jurídicas y de procuración de justicia internacionales (principalmente de EUA). En caso que la decisión de la SCJN hubiera sido contraria a lo previsto por ambos gobiernos, la resolución del asunto probablemente hubiera requerido una medida legislativa; una que presumiblemente hubiera sido bastante difícil de alcanzar dada la composición del congreso mexicano y la alta sensibilidad que el asunto podría generar entre los legisladores y la opinión pública mexicanos. ${ }^{184}$

\section{La resolución de la $S C J N$}

La resolución de la SCJN específicamente aborda el tema de si un nacional mexicano requiere ser juzgado en México por mandato de ley (artículo 4o.-CPF), lo que por ende impediría al Poder Ejecutivo federal autorizar su extradición (artículo 9.1 del Tratado de Extradición), incluso en "casos excepcionales" (artículo 14o., LEI).

Para comentar la resolución de la SCJN, reproduciremos el texto de las tres disposiciones en comento.

182 Primer Tribunal Colegiado en Materia Penal para el Primer Distrito (con sede en la ciudad de México, Distrito Federal) en el asunto de Óscar Malherbe de León (uno de los principales lugartenientes en la organización criminal Carrillo Fuentes (cartel de Juárez) y uno de los principales colaboradores de Amado Carrillo, alias "El Señor de los Cielos"). Torres, op. cit., nota 27.

183 Segundo Tribunal Colegiado en Materia Penal para el Segundo Distrito (con sede en Toluca, Estado de México) en el asunto de Everardo Arturo Páez Martínez (operador principal en la organización criminal Arellano Félix). Torres, op. cit., nota 27.

184 De hecho, Joshua Spector (Extraditing Mexican Nationals in the Fight Against International Narcotics Crimes, 31 U. Mich. J. L. Reform 1007 (1998)), sugería que un cambio en la política extraditoria de México probablemente requeriría una enmienda legislativa con el fin de permitir la extradición de nacionales. 
[Artículo 4o. Código Penal federal:] Los delitos cometidos en territorio extranjero por un mexicano contra mexicanos o contra extranjeros, o por un extranjero contra mexicanos, serán penados en la República, con arreglo a las leyes federales, si concurren los requisitos siguientes: I. Que el acusado se encuentre en la República; II. Que el reo no haya sido definitivamente juzgado en el país en que delinquió, y III. Que la infracción de que se le acuse tenga el carácter de delito en el país en que se ejecutó y en la República.

[Artículo 14o. Ley de Extradición Internacional:] Ningún mexicano podrá ser entregado a un Estado extranjero sino en casos excepcionales a juicio del Ejecutivo.

[Artículo 9o. Tratado de Extradición México-EUA:] 1. Ninguna de las dos partes contratantes estará obligada a entregar a sus nacionales, pero el Poder Ejecutivo de la parte requerida tendrá la facultad, si no se lo impiden sus leyes, de entregarlos si, a su entera discreción, lo estima procedente.

Por una parte, el Primer Tribunal Colegiado en Materia Penal del Primer Circuito, ${ }^{185}$ estimó que no procedía la extradición de los nacionales mexicanos solicitada por Estados Unidos de América. Consideró que si bien el artículo 9.1 del Tratado de Extradición México-EUA establece que ninguna de las partes está obligada a entregar a sus nacionales, ${ }^{186} \mathrm{si}$ no se lo impiden sus leyes, debe observarse lo previsto en el artículo 4o., $\mathrm{CPF}$, el cual dispone que serán juzgados en la república mexicana con arreglo a las leyes federales, los delitos cometidos en territorio extranjero por un mexicano, ${ }^{187}$ si concurren determinados requisitos. De esta forma, si se reúnen los requisitos contenidos en dicho artículo 4o., CPF, esta circunstancia impide que el Ejecutivo federal autorice la entrega vía extradición de un nacional. El tribunal mencionado señalaba que la frase "serán penados en la república, con arreglo a las leyes federales" establece un imperativo que constriñe a la autoridad a no entregar a un mexicano que haya cometido algún delito en el extranjero, y concomitantemente le impele a que sea juzgado por leyes mexicanas por los delitos que hubiese cometido.

Por su parte, el Segundo Tribunal Colegiado en Materia Penal del Segundo Circuito, ${ }^{188}$ sostuvo que los artículos 9.1 del Tratado de Extradi-

185 Al resolver el amparo en revisión número 5/98.

186 Lo que entonces puede discrecionalmente realizar el Poder Ejecutivo del Estado requerido.

187 "Los delitos cometidos en territorio extranjero por un mexicano contra mexicanos o contra extranjeros, o por un extranjero contra mexicanos, serán penados en la república, con arreglo a las leyes federales...".

188 Al resolver el amparo en revisión número 417/98. 
ción México-EUA y 14o., LEI, establecen una regla general por la cual los nacionales mexicanos no pueden ser objeto de extradición solicitada por Estados Unidos de América. La salvedad consistiría en que se tratara de "casos excepcionales a juicio del Ejecutivo federal". ${ }^{189}$ Esto es, conforme al segundo tribunal, no se está frente a una prohibición que niegue la extradición, sino de una limitación.

La SCJN indica ${ }^{190}$ que el artículo 9.1 del Tratado de Extradición México-EUA otorga una facultad discrecional al gobierno de México para que, a solicitud del gobierno de EUA, entregue mexicanos que han cometido delitos en EUA "si no se lo impiden sus leyes". La SCJN manifestó que esta expresión debe entenderse, en el caso mexicano, "como una prohibición al Poder Ejecutivo de acceder a la extradición demandada, pero sólo en el caso de que así lo establecieran la Constitución Política de los Estados Unidos Mexicanos o cualquier ley federal". ${ }^{191}$

Ahora bien, los impedimentos para extradición, tanto de nacionales como de extranjeros, están señalados de manera expresa por la Constitución Política de los Estados Unidos Mexicanos (CPEUM), la LEI y los tratados celebrados por México en la materia:

- La Constitución Política de los Estados Unidos Mexicanos. El artículo 15 constitucional prohíbe la celebración de tratados para la extradición de reos políticos y para delincuentes del orden común que hubieran tenido en el país donde cometieron el delito, la condición de esclavos. ${ }^{192}$

- La Ley de Extradición Internacional. Prescribe que no se concederá la extradición cuando el reclamado haya sido objeto de absolución, indulto o amnistía, o si se hubiere cumplido la condena relativa al delito que motiva el pedimento. ${ }^{193} \mathrm{La}$ extradición tampoco procede si faltare querella de parte legítima, ${ }^{194}$ hubiere prescrito la acción o la pena, ${ }^{195}$ el delito fue cometido dentro del ámbito de la jurisdic-

189 Artículo 14, LEI.

190 Tesis..., cit., nota 22.

191 Idem.

192 Esto igualmente se prevé en el artículo 8o, LEI. El artículo 15, CPEUM, igualmente prohíbe la celebración de tratados-convenios o tratados por que alteran las garantías y derechos establecidos en la Constitución para el hombre y el ciudadano.

193 Artículo 7I, LEI.

194 Si conforme a la legislación penal mexicana el delito exige ese requisito, artículo 7II, LEI.

195 Conforme a la legislación penal mexicana o a la legislación aplicable del Estado solicitante, artículo 7III, LEI. 
ción de los tribunales de la república, ${ }^{196}$ cuando el reclamado pueda "ser objeto de persecución política por el Estado solicitante". ${ }^{197}$ Igualmente es negada cuando el delito por el cual se solicita la extradición es del fuero militar. ${ }^{198}$

- El Tratado de Extradición México-EUA. La extradición es negada cuando el delito es político o de carácter político, ${ }^{199}$ si es un delito puramente militar, ${ }^{200}$ cuando el fugitivo hubiera sido sometido a proceso o haya sido juzgado y condenado o absuelto por la parte requerida por el mismo delito en que se apoye la solicitud de extradición, ${ }^{201}$ cuando la acción penal o la pena por la que se pida la extradición haya prescrito, ${ }^{202}$ y cuando el delito por el cual se solicita la extradición sea punible con la pena de muerte. ${ }^{203}$

Quedaba entonces analizar el artículo 4o., CPF, para definir el sentido de la disposición que señala que los delitos cometidos en el exterior por mexicanos "serán penados en la república".

La SCJN concluyó que del "análisis gramatical y sistemático del artículo 4o. del Código Penal federal, lleva a concluir que no contiene ninguna prohibición o impedimento a la extradición, sino que sustancialmente establece una regla del derecho aplicable". ${ }^{204}$ La SCJN explicó que dicha disposición estipula una regla procedimental para determinar la legislación que resultará aplicable cuando algún mexicano sea juzgado en México por delitos cometidos en el exterior.

La SCJN señaló que la frase del artículo 4o., CPF, en cuanto dispone: "serán penados en la república, con arreglo a las leyes federales", "significa que en caso de que un mexicano fuere juzgado en la república por un delito cometido en el extranjero, será sancionado con las penas que establezcan las leyes federales mexicanas y no conforme a las leyes del Esta-

\footnotetext{
196 Artículo 7-IV, LEI.

197 Artículo 8o., LEI.

198 Artículo 9o., LEI.

199 Artículo 5.1.

200 Artículo 5.3.

201 Artículo 6o.

202 Conforme a la legislación de cualquiera de las dos partes. Artículo 7o., Tratado de Extradición México-EUA.

203 En cuyo caso la parte requerida podrá negar la extradición, a menos que la parte requirente dé seguridades suficientes de que dicha pena no será impuesta; o de que si es impuesta, no será ejecutada. Artículo 8o.
}

204 Tesis..., cit., nota 22. 
do extranjero donde se le atribuye que delinquió, mas no que esté prohibida su extradición". 205

Así, el artículo 4o., CPF, no establece prohibición o impedimento expreso para la extradición independientemente de que el reclamado sea nacional o extranjero, o de que la extradición se solicite para someter al reclamado a proceso penal o para el efecto del cumplimiento de una pena.

Por ello, si bien el artículo 4o., CPF, establece que los delitos cometidos en territorio extranjero por un mexicano contra mexicanos o contra extranjeros, "serán penados en la república mexicana, con arreglo a las leyes federales"; 206 dicho precepto no constituye un obstáculo para la extradición de nacionales hacia EUA. Ello por dos motivos. No contiene una prohibición expresa sobre el particular. Adicionalmente porque los artículos 4o., CPF; 14, LEI, y 9.1 del Tratado de Extradición deben interpretarse en forma lógica y como partes de un mismo sistema legal.

De conformidad con el orden jerárquico establecido en el artículo 133 constitucional, el artículo 4o., CPF, establece una regla de aplicación general de jurisdicción y competencia. El artículo 14o., LEI, en consonancia con el artículo 9.1 del tratado, es un precepto de carácter especial y sustantivo en materia de extradiciones, y establece la norma tratándose de la extradición de nacionales mexicanos. En este sentido, el Ejecutivo federal debe ceñir su actuación al artículo 9.1 del tratado.

El artículo 4o., CPF, en relación con el artículo 32, LEI, ${ }^{207}$ es una disposición complementaria, cuya finalidad es la de evitar la impunidad. Cuando la Secretaría de Relaciones Exteriores niegue la extradición motivado por la calidad de mexicano del fugitivo, debe ponerlo a disposición del Ministerio Público y para ello remite el expediente al Ministerio Publico con el fin de que éste consigne el caso ante el tribunal competente si hubiere lugar a ello.

Si el supuesto del artículo 4o., CPF, estableciera una prohibición expresa para extraditar a nacionales, entonces se estaría frente a un conflicto de leyes entre los artículos 4o., CPF, y 14, LEI. En este caso, debería aplicarse el mencionado artículo 14, LEI, por ser la norma especial que regula la extradición.

205 Idem.

206 Cuando concurran los requisitos previstos en el propio numeral.

207 "Si el reclamado fuere mexicano y por ese solo motivo se rehusare la extradición, la Secretaría de Relaciones Exteriores notificará el acuerdo respectivo al detenido, y al procurador general de la República, poniéndolo a su disposición, y remitiéndole el expediente para que el Ministerio Público consigne el caso al tribunal competente si hubiere lugar a ello". 
Adicionalmente, debido a que actualmente la SCJN considera que los tratados tienen mayor jerarquía que la legislación federal, ${ }^{208}$ el artículo 4o., CPF, debe ceder frente a la norma establecida en el Tratado de Extradición México-EUA.

En consecuencia, tampoco prohíbe la extradición de nacionales mexicanos y éstos pueden ser extraditados de conformidad con el artículo 9.1 del Tratado de Extradición México-EUA. Si bien la redacción que utilizó la $\mathrm{SCJN}^{209}$ técnicamente podría hacer que la resolución sólo fuere aplicable al caso del referido tratado ${ }^{210}$ es previsible que los tribunales mexicanos aludirían a la resolución en comento de la SCJN para casos en que la parte requirente no fuera EUA. ${ }^{211}$

208 Tratados internacionales. Se ubican jerárquicamente por encima de las leyes federales y en un segundo plano respecto de la Constitución federal. 9a. época, Pleno, Semanario Judicial de la Federación y su Gaceta, t. X, noviembre de 1999, tesis P. LXXVII/99, p. 46. Amparo en revisión 1475/98. Sindicato Nacional de Controladores de Tránsito Aéreo, 11 de mayo de 1999. Unanimidad de diez votos. Ausente: José Vicente Aguinaco Alemán. Ponente: Humberto Román Palacios. Secretario: Antonio Espinoza Rangel. Nota: Esta tesis abandona el criterio Leyes federales y tratados internacionales. Tienen la misma jerarquía normativa, sustentado en la tesis P. C/92, publicada en la Gaceta del Semanario Judicial de la Federación, 8a. época, núm. 60, diciembre de 1992, p. 27. Para comentarios sobre dicha tesis, véase Becerra Ramírez, Manuel; Carpizo, Jorge; Corzo Sosa, Edgar y López-Ayllón, Sergio, "Tratados internacionales. Se ubican jerárquicamente por encima de las leyes federales y en un segundo plano respecto de la Constitución federal", Cuestiones Constitucionales, Revista Mexicana de Derecho Constitucional, México, núm. 3, julio-diciembre de 2000, pp. 169-208; Ramón Cossío, José, "La nueva jerarquía de los tratados internacionales”, Este País, México, núm. 107, febrero de 2000, pp. 3438; y Siqueiros, José Luis, “Tratados internacionales. Se ubican jerárquicamente por encima de las leyes federales y en un segundo plano respecto de la Constitución federal", Revista Mexicana de Derecho Internacional Privado, México, núm. 8, abril de 2000, pp. 111-115.

209 Dado que expresamente se refiere a dicho tratado: "Extradición. La posibilidad de que un mexicano sea juzgado en la república conforme al artículo 4o. del Código Penal federal, no impide al Poder Ejecutivo obsequiarla, ejerciendo la facultad discrecional que le concede el Tratado de Extradición entre Estados Unidos Mexicanos y Estados Unidos de América... De ahí se infiere, en lo que concierne al Estado mexicano, que el Poder Ejecutivo goza de la facultad discrecional de entregar a solicitud del gobierno de Estados Unidos de América, a los mexicanos que hayan cometido delitos en aquel país "si no se lo impiden sus leyes". Tesis..., cit., nota 22.

210 Al aclarar que esta nueva jurisprudencia no se ampliará ni aplicará a otros tratados de extradición, la ministro ponente Olga Sánchez Cordero comentó que este caso sólo compete al que tiene firmado México con EUA, específicamente en lo que se refiere el artículo 9o. Gómez, Francisco, "Extraditables, delincuentes mexicanos que reclaman en EU, resuelve la SCJN", La Crónica de Hoy, ciudad de México, 19 de enero de 2001.

211 Es de señalar que la proporción de solicitudes estadounidenses de extradición presentadas a México ha incrementado en los últimos años debido al mayor entendimiento entre autoridades de ambos países, véase supra texto que acompaña a las notas 102 y 103 así como 130 y 134. En tanto que en 1992, se estimaba que dos tercios de las solicitudes de extradición provenían de EUA; Labardini, op. cit., nota 9, p. 3, actualmente cerca del $90 \%$ de las solicitudes de extradición presentadas a México se originan en EUA, Mexico's Fight Against Drugs1998..., cit., nota 11, p. 55. 
La resolución de la SCJN también resulta importante porque adicionalmente ratifica la facultad discrecional del Poder Ejecutivo para extraditar nacionales mexicanos; facultad que, no obstante, debe ser debidamente fundamentada y motivada para ser ejercida. Adicionalmente, debe también considerarse que la resolución esencialmente sólo interpretó lo dispuesto por el artículo 4o., CPF, y no alguna otra disposición del Tratado de Extradición o de alguna ley federal mexicana, salvo por lo que se refiere a determinar alguna prohibición expresa que impidiera la extradición de nacionales mexicanos. ${ }^{212}$

El voto disidente en la SCJN ${ }^{213}$ manifestó que la CPEUM no cuenta con disposición alguna que justifique plenamente la entrega de mexicanos para ser sometidos a procesos penales en jurisdicciones extranjeras. ${ }^{214}$ Agregó que "debió efectuarse un estudio en su conjunto y en el caso, sólo se examina el precepto del Código Penal, en la parte que se refiere a las leyes federales y omite considerar la parte que se refiere al lugar donde deben ser penados". ${ }^{215}$ Debe señalarse que aparentemente en los debates privados entre los ministros de la SCJN, algunos especialistas en extradición manifestaron preocupación por posibles prejuicios raciales o legales que pueden darse en jurisdicciones extranjeras. ${ }^{216}$

Debido a que los casos que dieron origen a la contradicción de tesis causaron ejecutoria y son considerados res judicata, la resolución no afectó a los interesados en los correspondientes juicios de amparo. ${ }^{217}$ Sin embargo, la resolución de la SCJN sí afecta a todos los juicios de amparo en curso y aquellos que se presenten en el futuro. En este sentido, en otro juicio de amparo ${ }^{218}$ promovido por Everardo "Kitti" Páez, ${ }^{219}$ ocurrió la

212 De hecho, la ministro ponente, Olga Sánchez Cordero, aseguró que la resolución sólo interpretó el artículo 4, CPF, de tal forma que no hay mayores interpretaciones sobre el Tratado de Extradición entre México y EUA ni cualquier otra ley que pudiera incidir sobre dicho tratado. Sólo se resolvió la contradicción de criterio derivada de la aplicación de lo dicho por ordenamiento. Gómez, op. cit., nota 210.

213 Ministro Humberto Román Palacios, Voto Particular, Contradicción..., cit., nota 22.

214 Lizárraga, op. cit., nota 37.

215 Idem.

216 Idem.

217 En tanto que Óscar Malherbe no fue extraditado, Everardo "Kitti" Páez fue entregado a EUA el 4 de mayo de 2001. Procuraduría General de la República, Boletín de Prensa 287/01, 4 de mayo de 2001. Para información general véase Torres, Mario, "Aceptan extraditar a mexicanos a EUA”, El Universal, ciudad de México, 19 de enero de 2001. Asimismo, INCSR-1999..., cit., nota 164, p. 172.

218 Véase supra nota 170.

219 Una segunda resolución emitida por SRE el 31 de marzo del año 2000, también fue impugnada mediante juicio de amparo que fue en favor de Páez mediante sentencia emitida el 31 de julio 
primera determinación de un tribunal de alzada en que, basándose exclusivamente en la resolución de la SCJN, se autorizó la extradición de un nacional mexicano.

Finalmente, debemos mencionar que, al emitir la resolución en comento, la intención de la SCJN fue actualizar un artículo que data desde los años treinta ${ }^{220}$ con el que sustenta el Tratado de Extradición ${ }^{221}$ entre ambos países. Es decir, la SCJN consideró que en dicha época la delincuencia organizada no había rebasado fronteras ni era un problema de preocupación mundial, como sucede ahora que "En minutos, las bandas de delincuencia organizada cometen un fraude internacional, en minutos". 222

La SCJN tampoco quiso poner mayores candados a la extradición de nacionales debido a que el artículo 4o., CPF, y la Constitución son suficientemente claros. ${ }^{223}$

\section{CONCLUSIONES}

La Tesis de Contradicción 44/2000-PL emitida el 18 de enero del 2001 por la SCJN, tiene gran importancia en el ámbito de la cooperación internacional contra el crimen, y en específico en materia de cooperación antinarcóticos.

La sentencia no establece que todos los presuntos narcotraficantes o delincuentes peligrosos que sean requeridos por EUA, al estar acusados de algún delito en ese país, sean entregados sin reservas. De hecho confirma que la regla jurídica general es que los nacionales mexicanos no serán extraditados, salvo en casos de excepción.

del mismo año, en la que se insistía en el criterio de que el artículo 4, CPF, prohíbe la extradición de nacionales. Procuraduría General de la República, Boletín de Prensa 287/01, 4 de mayo de 2001.

220 Artículo 4, CPF.

221 Artículo 9.1.

222 Olga Sánchez Cordero, ministro ponente de la Contradicción..., cit., nota 22; citada en Jiménez, Norma, "Descartan ministros de la SCJN represalias de narcos", Milenio Diario, ciudad de México, 22 de enero de 2001.

223 Idem. Sánchez Cordero asimismo enfáticamente negó que los ministros hubieran recibido "presiones de Estados Unidos de América para resolver a favor de este tipo de extradiciones. Simplemente se revisó el artículo cuarto del Código Penal federal y se estableció que el criterio correcto que debe de aplicarse es que el Poder Ejecutivo tiene la facultad discrecional de extraditar a los presuntos delincuentes a quienes considere de alta peligrosidad y que sea procedente". 
La resolución tampoco afecta las vías jurídicas que los fugitivos a extraditar puedan presentar, ya que podrán seguir recurriendo al juicio amparo para objetar la decisión del Poder Ejecutivo en caso de que apruebe su extradición. El Ejecutivo es la instancia que goza de la facultad discrecional para entregar a los nacionales a las autoridades estadounidenses.

La decisión de la SCJN en esencia retiró, en México, un argumento que podría haber prevalecido impidiendo la extradición de mexicanos buscados en otro país. ${ }^{224}$ Sin embargo, esto no significa que la entrega de fugitivos de nacionalidad mexicana se realizará de forma inmediata, debido a que en sus apelaciones presentan diferentes argumentos que podrían impedir su extradición y cada uno de ellos debe ser debidamente valorado por los tribunales. Esto es, la resolución de la SCJN no estableció una "vía rápida" 225 para la entrega en extradición de nacionales mexicanos, sino que sólo resolvió una de varias indefiniciones en materia extraditoria, cerrando la puerta a la nacionalidad como impedimento para la extradición.

La resolución ratificó también las facultades discrecionales de la autoridad para conceder la extradición de nacionales mexicanos. ${ }^{226} \mathrm{Sin}$ embargo, pese a la revisión realizada por las autoridades mexicanas, el cambio en la política extraditoria y aún cuando se hayan entregado mexicanos en extradición — extradición ahora confirmada por la SCJN_, debe subrayarse que ello no garantiza que México habrá siempre de extraditar a ciudadanos mexicanos. La legislación contempla esta posibilidad en "casos excepcionales" 227 y el Tratado de Extradición expresamente no obliga a las partes a entregarse a sus nacionales, dejándolo a su criterio. ${ }^{228}$ Más

224 Qua minimum, los procesos de apelación de otros 14 nacionales mexicanos, véase Procuraduría General de la República, Boletín de Prensa 026/01, 19 de enero de 2001, han perdido vigencia sobre el punto específico de si la nacionalidad mexicana impide su extradición. Otros argumentos jurídicos que esgriman los afectados deberán ser debidamente evaluados por los tribunales.

225 O fast-track como también se le ha mencionado y que erróneamente se le dio este concepto en algunos medios. Cfr. "Podrían extraditar 250 reos mexicanos a EU", El Universal, ciudad de México, 19 de enero de 2001; Associated Press, Mexico's Supreme Court rules suspects can be extradited to United States, 19 de enero de 2001; Associated Press, Mexico says it is ready to extradite 14 suspects to the United States, 20 de enero de 2001.

226 La ministro ponente, Olga Sánchez Cordero, indicó que la última palabra sobre si se concede o no alguna extradición a Estados Unidos de América, la tendrá el gobierno de México en virtud de que los jueces federales sólo emitirán una opinión jurídica y corresponderá al Ejecutivo, en específico a la cancillería decidir si se hace la entrega o no del acusado. Gómez, op. cit., nota 210.

227 Artículo 14, Ley de Extradición Internacional. Para una aproximación sobre el concepto "casos excepcionales", véase supra texto que acompaña a las notas 171-181.

228 Artículo 9o. (2). 
importante aún, la extradición es un acto soberano. ${ }^{229} \mathrm{Al}$ efecto recuérdese que en febrero de 1999 se negó la extradición de cinco mexicanos acusados de lavado de dinero en el marco de la "Operación Casablanca". 230

Un importante efecto de la resolución de la SCJN ha sido el reactivamiento de solicitudes de extradición presentadas por EUA reclamando a mexicanos por presuntos delitos cometidos en ese Estado. ${ }^{231}$ El más reciente es el caso de José Luis García, alias “El Spider”, considerado uno de los principales distribuidores de drogas ilícitas en el sur de EUA y quien presuntamente operaba para la organización criminal de Carrillo Fuentes. ${ }^{232}$

Lo que más llama la atención de la resolución de la SCJN fue que su análisis se centró casi exclusivamente sobre la redacción del artículo 4o., $\mathrm{CPF}$, en relación con los artículos 14 de la Ley de Extradición Internacional y 9.1 del Tratado de Extradición México-EUA de 1978, sin tomar en consideración los desarrollos internacionales en materia de extradición. ${ }^{233}$

Se observa que no existe una definición o precisión del concepto de “casos excepcionales". Sin embargo, por motivos prácticos y para evitar un anquilosamiento del mismo, no debe haberlo. No obstante, la autoridad debe plenamente fundar, motivar y justificar por qué se trata de "casos excepcionales" un caso en particular. ${ }^{234}$

No obstante, la resolución de la SCJN parece mostrar un cambio de visiones entre sus miembros, y en la comunidad jurídica mexicana. Bien puede ser el resultado de un choque entre diferentes visiones jurídicas: una moderna, inmersa en el mundo contemporáneo, y otra con una visión más tradicional.

229 Bassiouni, International..., cit., nota 140, p. 1.

230 Véase supra texto que acompaña a las notas 157-163.

231 Hasta octubre de 2000 había 274 solicitudes de extradición de mexicanos, de las que 247 fueron presentadas por el gobierno de Estados Unidos de América, la mayoría vinculadas a narcotráfico. "Podrían extraditar 250 reos mexicanos a EUA", El Universal, ciudad de México, 19 de enero de 2001.

232 Gómez, Francisco, “Autorizan extraditar a presunto narco a EU”, El Universal, 20 de julio de 2001, p. 23.

233 Cfr. supra el apartado III, 3.

234 Véase supra texto que acompaña a las notas 171-181. 


\section{APÉNDICE}

Pese a la importancia de la resolución comentada, debido a que sólo interesaba analizar la extradición de nacionales mexicanos, la SCJN no aludió a otros temas de interés en materia de extradición, como la imposición de la cadena perpetua. Un tribunal mexicano ha resuelto que dos fugitivos no pueden ser extraditados a menos que EUA otorgue seguridades de que no serán objeto de cadena perpetua. ${ }^{235}$ La decisión estuvo basada en dos decisiones de la SCJN de la década de 1930 por la que se definió que la cadena perpetua era de naturaleza inusitada ${ }^{236} \mathrm{y}$, por ende, dentro de las prohibidas por el artículo 22 constitucional. ${ }^{237}$ Debido a lo anterior, por lo menos en otro caso de extradición, ${ }^{238}$ México ha solicitado seguridades de que EUA no aplicará esta pena. El tratado bilateral contempla seguridades en el caso pena de muerte, ${ }^{239}$ pero no alude a seguridades en el caso en que pueda imponerse la cadena perpetua. ${ }^{240}$ Esto ha desconcertado al gobierno de EUA, ya que la mayoría de los fugitivos solicitados en extradición normalmente han cometido delitos por los que puede imponerse la cadena perpetua. ${ }^{241}$ Dado que no es fácil obtener seguridades de que no se aplicará la pena de muerte, ${ }^{242}$ seguramente resultaría más

235 Se trata de dos narcotraficantes argentinos. INCSR-1999..., cit., nota 164, p. 172, y Warren, Importance of Extradition..., cit., nota 136.

236 "Es evidente que la cadena perpetua es un castigo inusual, ataca nuestras leyes, nuestro pasado y de hecho, y por tanto se encuentra entre las prohibidas por el artículo 22 de la Constitución". Segunda Sala, SCJN, Sichel, Enrico, Amparo administrativo en revisión 2339/30, 21 de enero de 1931, Semanario Judicial de la Federación, 5a. época, parte XXXI, p. 347. "Castigos inusuales son aquellos que chocan con el sentido general de la comunidad; en nuestros tiempos, dichos castigos son los azotes, la cadena perpetua, la confiscación y otras penas graves y trascendentales", Primera Sala, SCJN, Hoyos Huerta, Pedro, Amparo penal directo 2725/39, 11 de agosto de 1939, Semanario Judicial de la Federación, 5a. época, parte LXI, p. 2390.

237 "Quedan prohibidas las penas de mutilación y de infamia, la marca, los azotes, los palos, el tormento de cualquier especie, la multa excesiva, la confiscación de bienes y cualesquiera otras penas inusitadas y trascendentales. ...".

238 INCSR-1999..., cit., nota 164, p. 172.

239 "Cuando el delito por el cual se solicita la extradición sea punible con la pena de muerte conforme a las leyes de la parte requirente y las leyes de la parte requerida no permitan tal pena para ese delito, la extradición será rehusada, a menos que la parte requirente dé las seguridades que la parte requerida estime suficientes de que no se impondrá la pena de muerte o de que, si es impuesta, no será ejecutada". Artículo 8o.

240 Es de señalar que dichas seguridades sí se encuentran contempladas en el artículo IV del Tratado de Extradición entre Venezuela y EUA, Extradition Treaty, January 19 y 21, 1922, United States-Venezuela, entered into force April 14, 1923, 43 Stat. 1698, T. S. 675, reproducido en Abbel, Michael y Ristau, Bruno, International Judicial Assistance: Criminal, p. A-1045.

241 INCSR-1999..., cit., nota 164, p. 172.

242 Un ejemplo lo constituye Chuck Rosenthal, Fiscal de Distrito en el Condado Harris, California, 
complicado solicitarlas en el caso de la cadena perpetua; en especial cuando es un requisito no contemplado en el tratado respectivo. Sin embargo, ante la posibilidad de procesar penalmente al fugitivo, es posible que algunos fiscales opten por ofrecer dichas seguridades. Se ha informado ${ }^{243}$ que el pleno de la SCJN analizará el tema en agosto de 2001 y que, aparentemente, la mayoría de los ministros se encuentran a favor de autorizar la extradición en caso de que se pudiera imponer la cadena perpetua. ${ }^{244}$

EUA, quien aseguró que continuará exigiendo la pena de muerte en el caso de extranjeros, aún cuando fiscales en otras partes de EUA la han dejado de solicitar con el fin de lograr la extradición internacional del fugitivo. Hegstrom, Edward, "DA stands pat on foreigners, death penalty", The Houston Chronicle, 12 de enero de 2001, p. A21.

243 Aranda, op. cit., nota 9.

244 Adicionalmente debe considerarse que en casos en que puede imponerse la de pena de muerte a ciudadanos mexicanos aprehendidos en EUA, México ha solicitado que dicha pena sea conmutada por la de cadena perpetua. A mayor abundamiento, véase Quilantán Arenas, Rodolfo, La pena de muerte y la protección consular, México, Plaza y Valdés Editores, 1999. El ejemplo más reciente, infructuoso, es el de Gerardo Valdez. En un hecho sin precedentes, la propia Junta de Perdones de Oklahoma había recomendado la conmutación de la pena máxima por cadena perpetua, pero el gobernador Frank Keating rechazó la conmutación. Secretaría de Relaciones Exteriores, El gobernador de Oklahoma negó la clemencia al mexicano Gerardo Valdez Maltos, sentenciado a muerte, Comunicado de Prensa 147/01, 20 de julio de 2001. Adicionalmente, véase "México acusará a EUA en cortes internacionales", La Crónica, 21 de julio de 2001, primera plana; y Bonner, Raymond, "Mexican Killer is Refused Clemency by Oklahoma", The New York Times, 21 de julio de 2001, p. A7. 